\title{
MEASUREMENT OF ATTENUATION WITH AIRBORNE AND GROUND-BASED RADAR IN CONVECTIVE STORMS OVER LAND AND ITS MICROPHYSICAL IMPLICATIONS
}

\author{
Lin Tian', G. M. Heymsfield ${ }^{2}$ and R. C. Srivastava ${ }^{3}$ \\ 'Goddard Earth Science and Technology Center, University of Maryland, Baltimore \\ ${ }^{2}$ NASA Goddard Space Flight Center" \\ The University of Chicago
}

April. 2001

For Submission to Journal of Applied Meteorology

Corresponding Awthor Address:

Lin Tian. NASA, GSFC, Code 912. Greenbelt, MD 20771

Email: than@agnes.gsfenasa sov 


\begin{abstract}
ABSTRAC'T
Observations by the airborne X-band Doppler radar (EDOP) and the NCAR S-band polarimetric (S-POL) radar from two field experiments are used to evaluate the surface reference technique (SRT) for measuring the path integrated attenuation (PIA) and to study attenuation in deep convective storms. The EDOP, flying at an altitude of $20 \mathrm{~km}$, uses a nadir beam and a forward pointing beam. It is found that over land, the surface scattering cross-section is highly variable at nadir incidence but relatively stable at forward incidence. It is concluded that measurement by the forward beam provides a viable technique for measuring PIA using the SRT. Vertical profiles of peak attenuation coefficient are derived in two deep convective stoms by the dual-wavelength method. Using the measured Doppler velocity, the reflectivities at the two wavelengths. the differential reflectivity and the estimated attenuation coefficients, it is shown that: supercooled drops and (dry) ice particles probably co-existed above the melting level in regions of updraft, that water-coated partially melted ice particles probably contributed to high attenuation below the melting level, and that the data are not readily explained in terms of a gamma function raindrop size distribution.
\end{abstract}




\section{Introduction}

Airborne and satellite borne radars typically operate at wavelengths less than $3 \mathrm{~cm}$ to reduce the overall size and weight of the payload, and to obtain adequate spatial resolution. The most notable satellite-borne radar is the Tropical Rain Measuring Mission Precipitation Radar (TRMM-PR) which operates at a wavelengih of $2.17 \mathrm{~cm}$ (Kummerow et al. 1998). The TRMM$\mathrm{PR}$ is used to estimate rainfall, $\mathrm{R}$, from the radar reflectivity, $Z$, by means of empirical $Z-R$ equations. However, at these shorter wavelengths, the microwave radiation suffers significant attenuation in passing through precipitating storms. The attenuation is significant in rain and can be very pronounced in the presence of large wet ice particles, such as, melting or water-coated hail. It is important to correct for the attenuation in order to estimate the rainfall more accurately. The study and observation of attenuation can help us to improve the algorithms for attenuation correction, and thereby improve the estimation of precipitation by the PR. For a given wavelength and polarization state, the microwave attenuation depends upon the size, concentration. shape, orientation and composition of the hydrometeors (Battan 1975). However, in situ microphysics are difficult to obtain in high reflectivity, highly attenuating core. Therefore. the measurement of attenuation can also help us to understand the microphysics of precipitation.

Direct measurement of attenuation is difficult. Three methods have been used for both ground-based and airborne radars. The dual wavelength method measures reflectivity at the attenuating wavelength (e.g., $3 \mathrm{~cm}$ ) and at a non-attenuating wavelength (e.g., $10 \mathrm{~cm}$ ) simultaneously in a common volume. The difference of the two reflectivity factors ${ }^{1}$ gives the two-way integrated attenuation between the radar and the common volume along the path of the attenuating beam; this is usually referred to as the path-integrated attenuation (PIA). This method assumes that the wavelength dependence of the back-scattering cross-sections of the scatterers is accounted for: this can be done if the particles are in the Rayleigh scattering region (Eccles and

\footnotetext{
The equivalent reflectivity factor will hereafter be referred to simply as reflectivily for the sake of hrevity.
} 
Mueller 1971; Meneghini et al. 1992; Bolen and Chandrasekar 2000). The second method, called the dual-radar method, utilizes two-spaced radars operating at the attenuating wavelength to map the reflectivity field from two different aspects. The two reflectivity fields can be used to obtain the specific attenuation. This method has been used for airborne radar (Testud and Amayenc 1989) and for ground-based radar (Srivastava and Tian 1996; Tian and Srivastava 1996). The dual-radar method does not require that the scatterers be in the Rayleigh range. The third method involves the use of a reference target of known reflectivity. When a surface target is used as the reference, the method is called the surface reference technique (SRT) (e.g., Meneghini et al. 1983). In this method, the 'reference' radar cross-section of the surface is first determined in the absence of attenuation. In practice this means measuring the reflectivity of the ground in a precipitation-free area in close proximity to the precipitating area. When measurements of the ground cross-section are made through precipitation any decrease from the reference crosssection is attributed to two-way PIA between the radar and the surface. The SRT is used in processing TRMM-PR data (Iguchi et al. 2000).

The success and accuracy of the SRT depends upon the stability of the radar cross-section of the surface. A number of studies have been devoted to study the dependence of the surface reflectivity on the angle of incidence, especially over the oceans, which give a relatively constant microwave reflection. Limited studies of the SRT over land have been reported to date (Meneghini et. al. 2000). In general, this is because the radar cross-section of land surface can be highly variable particularly at near-nadir incidence angles. A second concern is the change in the surface cross-section between raining and non-raining conditions due to wetting and other surface changes accompanying precipitation.

Several field experiments were conducted in support of TRMM. Of interest to us is the Texas and Florida Under Flights Experiment-B (TEFLUN-B) held near Melbourne. Florida in August and September 1998 and the TRMM Land-Biosphere Atmosphere (TRMM-LBA) held in 
southwestern Amazon in January and February 1999. ${ }^{2}$ A number of universities and research laboratories participated in the experiments and deployed a variety of instruments.

In this paper, we present selected instances of high PIA observed over land at high incidence angle using NASA's ER-2 high altitude aircraft. The observations were obtained with a radar mounted on the ER-2 in Brazil and Florida during TRMM field campaigns. We compare the observations by the airborne X-band ER-2 Doppler Radar (EDOP) with nearly simultaneous and collocated observations obtained by a S-band ground-based radar (the National Center for Atmospheric Research. S-POL radar) that is not subject to significant attenuation. The characteristics of the radars we use in this study are summarized in sections $2 b$ and $3 b$. We shall compare the attenuation derived by the SRT from EDOP with attenuation derived by the dual wavelength method using EDOP and S-Pol described in Section 3 and 4 . We shall interpret the measured attenuation in terms of microphysical properties of the precipitation in Section 5.

\section{Attenuation Observed by EDOP Using SRT}

\section{a. SRT method}

We briefly review the method of obtaining PIA by the SRT and present an eximple of a storm that shows significant PIA. The observed return power from the surface, $P$, is related in its normalized radar cross-section, $\sigma_{l}^{0}$, by:

$$
P_{0}=C_{s} \frac{\sigma_{L}^{0}}{r^{2}}
$$

where $C_{v}$ is a constant depending upon the radar characteristics and the angle of incidence. In the presence of precipitation. the apparent normalized radar cross-section of the surface. $\sigma_{R}^{(j}$. is related to the normalized radar cross-section in the absence of precipitation, $\sigma_{v R}^{\prime \prime}$, by:

$$
\sigma_{R}^{0}=\sigma_{V R}^{0}-A
$$

\footnotetext{
" http://www eosdata.gsfc.nasa.gov/CAMPAIGN.DOC/TRMM-FE
} 
where $A$ is the two-way path-integrated attenuation and $\sigma^{0}=10 \log \sigma_{L}^{0}$ where $\sigma^{0}$ is in $\mathrm{dB}$. Because $\sigma_{N R}^{0}$ is not measurable, it is replaced by a reference value, $\left\langle\sigma_{N R}^{0}\right\rangle$, an average of $\sigma_{N R}^{0}$ along the flight track for an adjacent rain-free area. Using this reference value, the estimated PIA is:

$$
\tilde{A}=\left\langle\sigma_{N R}^{0}\right\rangle-\sigma_{R}^{0}
$$

Because the reference value can be different from the true surface radar cross-section, $\tilde{A}$ can differ from the true PIA. A. Differences between $\left\langle\sigma_{N R}^{0}\right\rangle$ and $\sigma_{v R}^{0}$ may be due to the variability of the surface, and changes of surface scattering due to changes in wind, vegetation, soil moisture. ete (Ulaby 1982). We need to know the magnitude of this variability in order to assess limitations in the measurement of the PIA.

b. Application of SRT to EDOP data

The Doppler radar (EDOP) mounted on the NASA's ER-2 aircraft operates at 3-cm wavelength. It has two fixed antennas, one pointing at nadir and the second pointing $33.8^{\prime \prime}$ ahead of nadir. The antennas are identical with a beam width of $3^{\prime \prime}$ (circular) defining a footprint at surface of about $1 \mathrm{~km}$ at nadir assuming ER-2 17ies $20 \mathrm{~km}$ above the surface. The ER-2 ground speed is about $210 \mathrm{~ms}^{-1}$ and the integration time for the data processing is $0.5 \mathrm{sec}$. These two values imply that the surface cross-section is over sampled with one sample being measured every $100 \mathrm{~m}$ along the flight track, and 10 samples are obtained over one beam width. The range resolution of the radar is $37.5 \mathrm{~m}$. Additional details about the radar and the data processing maty be found in Heymsfield et al. (1996).

Figure la shows a histogram of the surface reflectivity observed by EDOP from the nadir and forward antennas for a cloud and precipitation free region over the ocean off the Gulf coast of Florida. The data are typical in that surface reflectivity of the ocean surface at nadir incidence has small fluctuations of $\pm 1 d B$ while the echo at $33.8^{\circ}$ incidence is more variable having a standard deviation of about $2 \mathrm{~dB}$. The situation is very different over land (Fig. 1b). Al nadir 
incidence the reflectivity is highly variable having a standard deviation of about $4 \mathrm{~dB}$. At forward incidence, however, the surface echo over land shows variability similar to that over the ocean with a standard deviation of about $2 \mathrm{~dB}$. The importance of distributions such as those in Fig. 1 to the SRT is that the variability of the surface return limits the minimum PIA that can be measured and also gives an estimate of error in measured PIA due to surface variability. We see that over land, the SRT is subject to larger errors at nadir incidence, while at forward incidence PIA can be measured with the same accuracy as over the oceans. The surface echo characteristics at nadir and forward incidence are similar to Fig. Ib for a variety of regions, including the southeastern coast of the U.S., the western U.S.. and the Amazon rain forest in Brazil. We may conclude that the variability of surface return over land at $33.8^{\prime \prime}$ incidence angle is about $\pm 2 d B$. Therefore. PIA greater than about $2 \mathrm{~dB}$ can be measured over land at high incidence angle (Other sources of error are likely to be smaller than $2 \mathrm{~dB}$.)

It is emphasized that it is not necessary to measure the absolute value of the surface return since the SRT is a differential technique. It is important, however, that the magnitude of the surface return does not change as a consequence of wetting of the surface by the rain. since the SRT will attribute any such change to PIA. In the cases studied so far with the EDOP radar. no significant change in the surface cross-section has been observed at the transition between rainy and clear conditions for non-nadir incidence

An example of the observation by EDOP is shown in Fig. 2 from an East-West flight over land near Ji Parana, Brazil on 12 February 1999. Figures $2 a$ and $2 b$ show the reflectivities measured by the nadir and forward antennas; Figure $2 \mathrm{c}$ shows the surface cross-section. $\sigma^{0}$. measured by the nadir (dotted) and forward-pointing (solid) antennas. The flight track covers a convective cell embedded in stratiform rain. The reflectivity measured by the EDOP nadir antenna shows that, in the cell, the $10 \mathrm{dBZ}$ contour reaches a height of $13 \mathrm{~km}$ and the peak reflectivity is $56 \mathrm{dBZ}$ at a height of $4 \mathrm{~km}$ at a dislance of about $30 \mathrm{~km}$. 
A note about the terminology and coordinate system may be helpful here. In Fig. 2 and subsequently, the reflectivities measured by the EDOP forward and nadir-pointing beams will be denoted as $Z_{v f}$ and $Z_{x n}$ respectively. $Z_{*}$ will represent the reflectivity measured by the S-POL radar. All altitudes are above ground level (AGL) unless stated otherwise. The $\mathrm{x}$-coordinate in the vertical sections is the distance along the flight path from some arbitrary origin: this is the same as the distance along the surface. It is to be noted that the forward reflectivity is measured when the radar is ahead of the $\mathrm{x}$-coordinate shown in the figure: for the surface observation, it is ahead by $20 \mathrm{~km} \times \tan \left(33.8^{\circ}\right)$, or $13.4 \mathrm{~km}$. The PIA inferred from the forward beam is along a slant path that terminates at the surface at the $x$-coordinate shown.

Returning to Fig. 2a, the nadir pointing antenna shows a low surface reflectivity region situated below a region of high reflectivity at a distance of about $40 \mathrm{~km}$. The nadir surface crosssection. $\sigma^{0}$ (Fig. $2 \mathrm{c}$ - dotted line) shows that this low reflectivity is probably due to attenuation: however, it is difficult to interpret the decrease in the cross-section in terms of PIA with confidence because of the large fluctuations in the background surface cross-section at nadir incidence. The storm reflectivity measured by the forward-pointing antenna (Fig. 2b) is similar to the nadir reflectivity except that a lower reflectivity exists at about $45 \mathrm{~km}$ distance. The relative displacement of the minimum of the surface cross-sections for the forward and nadir beams is related to the beam orientations; the forward beam suffers greater attenuation along a slant path that intersects the ground ahead of the nadir beam. The integrated attenuation in the forward beam is greater probably because the slant paths are longer. In contrast to the nadir beam. the background $\sigma^{\prime}$ (regions of little or no precipitation) measured by the forward beam (Fig. 2c-solid line) is stable. The forward minimum $\sigma^{0}$ of $-23 \mathrm{~dB}$ at $45 \mathrm{~km}$, compared with the background $\sigma^{0}$ of $-8 \mathrm{~dB}$. yields a two-way PIA of $15 \mathrm{~dB}$. It is encouraging to note that notwithstanding the large fluctuations in the nadir $\sigma^{\circ}$, the structure of the dip in the nadir $\sigma^{\prime \prime}$ is 
very similar to that of the forward $\sigma^{0}$. The double dip in the nadir $\sigma^{0}$ seems to be correlated with the storm structure at high levels.

During the two TRMM field campaigns, the ER-2 flew over numerous deep convective storms. The cloud tops, defined by the $10 \mathrm{dBZ}$ contour, reached up to about $14 \mathrm{~km}$; many of these storms also showed large PIA. Table 1 lists eight such cases of storms over land. Most cases have rather intense convection as indicated by the fact that the $40 \mathrm{dBZ}$ contour reached 15 $\mathrm{km}$ and the PIA exceeded about $20 \mathrm{~dB}$; such PIA is large for the two-way path of about $20 \mathrm{~km}$. In the following, we present two cases from the table. One of the cases is from Florida and the other is from Brazil. These cases were selected because the S-POL radar also observed these storms nearly simultaneously. SPOL and EDOP can be used together to provide an independent estimate of attenuation using a dual-wavelength method.

\section{Dual-Wavelength Method and SPOL Data Processing}

a. Dual-wavelength method and method of Using $k-Z_{s}$ relation

The dual wavelength method takes the difference of the reflectivities observed by the $S$ $\operatorname{POL}\left(Z_{v}, \mathrm{~dB}\right)$ and the $\operatorname{EDOP}\left(Z_{i}, \mathrm{~dB}\right)$ radars. In general. we can write:

$$
Z_{i}-Z_{\imath}=2 \int_{0}^{\prime} k\left(r^{\prime}\right) d r^{\prime}+\delta
$$

where $\delta$ is the difference in reflectivity due to the departure from Rayleigh scattering. For particles much smaller than the wavelength, $\delta=0$. Figure 3 shows $\delta$ for a mono-disperse distribution of spherical water drops of different diameters. We see that $\delta$ can be taken as zero if the drop diameter is less than about $2.5 \mathrm{~mm}$. A minimum $\delta$ of about $-3.5 \mathrm{~dB}$ occurs for drops of diameter about 6-8 $\mathrm{mm}$.

Since $10 \mathrm{~cm}$ wavelength radiation is subject to little or no attenuation, an expected PIA at 3.2 cm may be calculated from the power-law empirical $k-Z_{\text {s }}$ equation:

$$
k=a Z^{\prime \prime}, a=2.9 \times 10^{-\downarrow} . b=0.72
$$


by evaluating the integral of $2 a Z^{h}$ along the path of the EDOP beam. In equation (4), $\mathrm{k}$ is in $\mathrm{dB}$ $\mathrm{km}^{-1}$ and $Z_{s}$ is in $\mathrm{mm}^{6} \mathrm{~m}^{-3}$. The values of $a$ and $b$ are taken from Battan (1975). Equation (4) is applicable for the modified Marshall-Palmer distribution, a wavelength of $3.2 \mathrm{~cm}$ and spherical raindrops having a temperature of $0^{\circ} \mathrm{C}$. It may be noted that the PIAs or attenuations estimated from the above two methods, involving additional data from the S-POL radar, are independent of the PIA deduced from the SRT.

b. SPOL data processing

The NCAR SPOL radar is transportable ground-based dual-polarization radar operated at $10 \mathrm{~cm}$ wavelength. The beamwidth of the S-POL antenna is $0.91^{\prime \prime}$ (circular) and its range resolution is $150 \mathrm{~m}$. Besides Doppler parameters, S-Pol measures reflectivity and polarization quantities, such as, the differential reflectivity (ZDR) and the linear depolarization ratio (LDR). Further details for S-Pol may be found at the website. ${ }^{3}$

S-POL radar observations were processed as follows. Data from the volume scan nearest in time and space to the ER-2 overflight was interpolated onto a grid coincident with the vertical plane mapped out by the ER-2 radar. The EDOP has generally higher resolution than S-POL. For example, at $50 \mathrm{~km}$ distance from the S-POL. the approximate distance of S-POL from the stom cases to be discussed, the resolution of the S-POL beam is about $0.87 \mathrm{~km}$ in the cross-beam direction and $0.15 \mathrm{~km}$ in the along-beam direction; for the EDOP radar, the cross-beam resolution is about $0.76 \mathrm{~km}$ at $5 \mathrm{~km}$ height and the along-beam resolution is a constant 0.0375 $\mathrm{km}$. Spatial averaging of the data was performed in order to make their resolutions approximately comparable. Such averaging should reduce errors in estimating PIA or attenuation by the dual wavelength method. Still, we can expect errors, especially in regions of high

\footnotetext{
'http://www.atd.ucar.edu.
} 
gradients. Differences due to temporal displacements in data can also cause errors; no attempt was made for time interpolations.

In the next section. we present data for the two storms and attempt to validate the attenuation inferred from the SRT. The attenuation is interpreted using a) dual-wavelength in terms of the microphysical structure of the storms and b) SPOL multi parameter data.

\section{Case Studies of Large PIA}

\section{a. A Storm on 15 August. 1998 in Florida}

On 15 August 1998, the ER-2 flew over a $60 \mathrm{~km}$ long N-S line of vigorous convective cells during 2223-2230 UTC. The merging of the East and West Coast sea breezes triggered the cells. Nearly simultaneous and co-located observations by the S-POL were used to construct Fig. 4, which shows (a) reflectivity, $Z_{s}$ (b) ZDR, and (c) LDR during 2224-2237 UTC at $8 \mathrm{~km}$ height. At this height. the maximum reflectivity is about $58 \mathrm{dBZ}$ (indicated by + ) about $1 \mathrm{~km}$ west of the ER-2 flight line whose projection is shown by the solid line. Coincident with the high reflectivity core, the ZDR is near zero (Fig. 4b) and the LDR is greater than $-18 \mathrm{~dB}$ (Fig. 4c): this generaliy indicates the presence of wet hail (Doviak and Zinic 1993).

Figure 5 shows rertical sections of the reflectivity, $Z_{s}$. constructed from S-POL radit data along the flight track (Fig. 5a), the reflectivity, $Z_{y f}$, measured by the forward-pointing beam of the EDOP radar (Fig. 5b), the PIA deduced by the SRT (Fig. 5c, solid line), and the PIAs deduced by the two methods outlined above (Fig. 5c, dotted and dashed lines). We see that the 0 $10 \mathrm{dBZ} Z$, contour reaches a height of about $15 \mathrm{~km}$ and the $40-50 \mathrm{dBZ}$ contour reaches a height of about $14 \mathrm{~km}$ : these indicate an intense storm. The maximum reflectivities seen by S-POL and EDOP are 55 and $53 \mathrm{dBZ}$ respectively ("+"in Figs.5a and 5b). Such high reflectivities suggest that hail may have been present in the storm. As pointed out above, wet hail was probably present west of the flight path. 
The maximum PIA measured by the SRT along the forward beam is $25 \mathrm{~dB}$ at a distance of about $72 \mathrm{~km}$ (Fig. 5c). The PIA obtained by integrating the empirical $k-Z_{s}$ equation (4) along the forward-pointing beim from storm top to $1 \mathrm{~km}$ height AGL is shown by the dotted line; its peak value is about $30 \mathrm{~dB}$. [Reliable $Z_{s}$ were not available below $1 \mathrm{~km}$ height because of radar scan limitations and ground clutter.] The peak PIA from $Z_{s}$ is about $5 \mathrm{~dB}$ greater than that from the SRT. This discrepancy is greater than the estimated uncertainty (about $2 \mathrm{~dB}$ ) in the SRT. Moreover, the contribution of attenuation below $1 \mathrm{~km}$ height will make the discrepancy even worse. Therefore, we can probably attribute the difference between the PIAs deduced by the SRT and from the $Z$, to inadequacies in the empirical $k-Z_{s}$ equation, and presence of hydrometeors with characteristics other than those on which the empirical $k-Z_{s}$ equation is based.

The PIA deduced from the difference, $Z_{s}-Z_{y j}$, along the forward beam from flight altitude down to a height of $1 \mathrm{~km}$ (dashed line) generally parailels the other two PIA curves; its peak value, about $28 \mathrm{~dB}$. is in good agreement with the peak PIA deduced from the SRT; this is remarkable considering the data processing which involved interpolation, averaging, temporal and spatial displacements. and resolution differences between the S-POL and EDOP radar data sets.

It is also possible to estimate range-resolved PIA by taking the differences of $Z_{s}$ and $Z_{x j}$ at different heights. This procedure would yield the attenuation along slant paths. From a microphysical standpoint. vertically resolved PIAs are of greater interest, especially in deer convective clouds. Therefore, we shall concentrate on range-resolved attenuation inferred from $Z_{s}$ and $Z_{x n}$, the reflectivity observed by the nadir beam of the EDOP.

Before presenting the range-resolved attenuation, we compared the reflectivities measured by the S-POL and EDOP radars because the accuracy of the dual-wavelength method of PIA estimation depends upon the accuracy of the radar calibration besides the assumption of 
Rayleigh scattering. Figure 6 is a scatter plot of $Z_{s}$ vs $Z_{x n}$ for the storm in Fig. 5. Except for a relatively small fraction of the points, $Z_{s}$ and $Z_{x n}$ scatter around the one-to-one line. The standard errors of $Z_{s}$ and $Z_{x n}$ are about 1-2 dB, implying a standard error in $Z_{s}-Z_{x n}$ of about $1.5-3 \mathrm{~dB}$. This is confirmed by the scatter plots. Therefore, we should be able to measure PIAs greater than $2-3 \mathrm{~dB}$ by the dual wavelength method with a 2-3 $\mathrm{dB}$ accuracy. It should be noted that the accuracy of the range-resolved attenuation does not depend upon the absolute accuracy in the measurement of the reflectivities.

Figure $7 \mathrm{a}$ is a plot of the S-POL reflectivities, $Z_{s}$. along the paths of the nadir beam at the heights of $1,2,3,4,5$, and $6 \mathrm{~km}$. Figure $7 \mathrm{~b}$ shows dual wavelength PlAs for the nadir beam from storm top to those heights. Figure $7 \mathrm{c}$ shows the PIA from integration of the empirical $k-Z_{\text {s }}$ equation along the nadir paths. The PIA curves in Figs. $7 \mathrm{~b}$ and $7 \mathrm{c}$ have similat shapes but differ in magnitude. The two sets of curves can be made to agree better by 'tuning' constants $a$ and $b$ in the (4) which depend on the drop size distribution. The main peaks of the PIA in Fig. 7 b occur at a distance of about $69 \mathrm{~km}$ in the region of highest reflectivity. A second peak occurs at about 75 $\mathrm{km}$ in the region of sharp gradient of reflectivity. The PIA in the latter region may not be reliable because of the reasons mentioned earlier. It is encouraging to note that the curves for the higher heights are generally below the curves for the lower heights; the opposite would be physically implausible except in the presence of significant concentrations of non-Rayleigh scatterers. Therefore, we may conclude with some confidence that non-Rayleigh scatterers, such as large hail, were not present in significant concentrations.

\section{b. A Storm on 10 Februan; 1999 in Brazil}

The EDOP flew over a line of convective storms in Brazil during 1811-1816 UTC,10 February 1999. The southern most cell were located about $50 \mathrm{~km}$ north of the S-POL radar. Figure 8 shows S-POL reflectivity at $3 \mathrm{~km}$ height; it was constructed from the $1810-1815$ UTC S-POL volume scan. 
Figure 9a, similar to Fig. 5a, indicates that $0-10 \mathrm{dBZ}$ and the $40-50 \mathrm{dBZ}$ contours reach heights of about $15 \mathrm{~km}$ and $8 \mathrm{~km}$, respectively. The maximum reflectivity ("+" in Fig. 9a) is 52 $\mathrm{dBZ}$, lower than the Florida storm discussed previously. The maximum reflectivity from forward beam (Fig. 9b) is only $50 \mathrm{dBZ}$. We also note that the shape of the low reflectivity region (Fig. $9 \mathrm{~b}, 30-32 \mathrm{~km}$ ) is aligned in the direction of the forward beam, a signature of attenuation (Atlas and Banks, 1951). The two-way PIA in the direction of the forward-beam derived by the SRT (Fig. 9c, solid line) show's a maximum PIA of $29 \mathrm{~dB}$ at a distance of about $32 \mathrm{~km}$. The PIA along the forward path from storm top to $1 \mathrm{~km}$ height from the empirical $k-Z_{s}$ equation (Fig. 9c. dashed line) is similar in shape to the SRT curve, but is substantially lower; a peak value of about $12 \mathrm{~dB}$ at $32 \mathrm{~km}$ distance versus $29 \mathrm{~dB}$ for SRT. The PIA to $1 \mathrm{~km}$ height along the forward beam deduced by the dual wavelength method (Fig. 9c, dotted line) also parallels the SRT but its peak value of about $19 \mathrm{~dB}$ is much smaller than the PIA from the SRT. This peak would have been closer to the maximum SRT value of $29 \mathrm{~dB}$ if the attenuation below $1 \mathrm{~km}$ height could have been included. but would still fall short of the maximum SRT value. Other discrepancies between the dual wavelength PIA and the SRT PIA occur mainly in regions of high gradients and at storm edges for reasons already noted.

Figure 10 is a scatter plot of $Z_{8}$ against $Z_{n n}$, similar to Fig. 6. The $X$-band and S-band reflectivities have more scatter about the one-to-one lines than that the Florida storm (Fig. 6). One probable reason is that for the previous Florida case, an RHI scan was available in close proximity to the EDOP flight plane and time. The $Z$, shown was essentially obtained by interpolating the $Z_{s}$ values from the RHI grid to the grid of the EDOP observations. In the case of the Brazil storm, however, a complete volume scan with PPIs at different elevation angles had to be used to construct the vertical plane. As stated before, the volume scan took about $5 \mathrm{~min}$. In the EDOP observations, there is a systematic progression of time with horizontal distance during 
data acquisition leading to a systematic difference between the times at which the S-POL and EDOP observations are acquired. No attempt was made to correct for differences in time.

Figure 11 for the Brazil storm is similar to Fig. 7 for the Florida storm. We again note that the PIA curves derived from the empirical $k-Z_{s}$ equation (Fig. 11c) are similar to the dualwavelength PIA curves (Fig. 11b) but they are considerably smaller in magnitude. As mentioned previously, better agreement could be obtained by 'tuning' the coefficient and exponent in the empirical $k-Z_{s}$.

The peak two-way PIAs and range-resolved attenuation along a vertical path (vertical solid line in Fig. 7b and Fig. 11 b) for Florida and Brazil storm are summarized in Table 2 and 3 for later discussion. The $\mathrm{Z}$ and ZDR in the tables were obtained from Fig. 16 and 18 to be discussed later in section $5 \mathrm{~b}$. In Table 3 , there is a negative attenuation in the beight interval, 1.5 $2.0 \mathrm{~km}$ which is larger than the $1.5 \mathrm{~dB}$ uncertainty estimated in the dual-wavelength reflectivity ratio. In deriving the range-resolved attenuation, we take the difference of the reflectivity ratio at the two heights. Also. as noted earlier, the observations for Brazil storm are probably subject to greater processing errors than the Florida storm. Thus the negative attenuation may be apparent. being the results of various sources of error. Another possibility is that non-Rayleigh scatterers were present in significant concentration in this height interval.

\section{Inferred Microphysics from Theory and Observations}

In both the Florida and Brazil storms, the attenuation between the storm top and $5 \mathrm{~km}$ height, estimated by the dual-wavelength method, was $1 \mathrm{~dB}$ or less (Table 2 and 3). The depth of the storm with the storm top ranged from $10-15 \mathrm{~km}$ agl. ensures that ice particles were present in the storm. The small attenuation above $5 \mathrm{~km}$ means that this region was dominated by ice particles and that wet ice particles which attenuate strongly were not present in significant concentrations. As mentioned before. LDR from SPOL showed evidence of wet hail at an altitude of $8 \mathrm{~km}$ in the Florida storm, hut this was to the West of the flight path of EDOP. In that 
region, the polarimetric data (not shown) also showed evidence of wet ice particles below the melting level. Furthermore large hail, greater than say $1 \mathrm{~cm}$ diameter, was also probably not present in significant concentrations because it would have been manifested by its Mie scattering effects at the shorter wavelength. Interpretation of the attenuation coefficients inferred for the lower levels is more problematical because raindrops and mixed phase particles were likely to have been present below the melting level.

In this section, we attempt to interpret the peak attenuation estimated above in terms of the hydrometeors responsible for the attenuation. For this purpose, we shall primarily use the attenuations obtained by the dual-wavelength method, since this method yields range-resolved attenuation coefficients. Because of the great complexity and diversity of the possible distributions of hydrometeors in deep convective storms. conclusions from our limited data set must be considered to be qualitative and preliminary, and in part even speculative since there is no direct validation.

In order to better understand the process below the freezing level, we also use ZDR observed by the S-POL radar and the Doppler velocity. $V_{11}$, observed by the nitlir beam of the EDOP radar. Further, we shall make use of theoretical relationships between reflectivity. attenuation coefficient and Zdr for Gamma function distribution of raindrop sizes. These relationships provide a 'base reference' case for interpreting the data. We begin with the theoretical relationships.

\section{a. Theoretical Relationship}

1) Attenuation, Reflectivity and Median Volume Diameter:

We assume a gamma rain drop size distribution (Ulbrich. 1983):

$$
N(D)=N_{0} D^{\mu} \exp (-\Lambda D)
$$

where $V(D) \Delta D$ is the concentration of drops of diameter $D$ to $D+\Delta D$ and $N_{0}, \mu$ and $\Lambda$ are parameters of the distribution. The exponential distribution is a special case of the $(6)(\mu=0)$. 
To facilitate analytical manipulations, we assume that the diameter ranges from zero to infinity in (6): qualitatively similar results are obtained when a non-zero minimum diameter and a finite maximum diameter are considered. The median volume diameter, $D_{0}$, of the above distribution is given approximately by:

$$
D_{0}=\frac{3.67+\mu}{\Lambda}
$$

The reflectivity factor is given by:

$$
Z=c_{-}\left[\frac{N_{0}}{\Lambda^{\mu}}\right] \frac{\Gamma(7+\mu)}{\Lambda^{7}}
$$

The extinction cross-section of a spherical raindrop can be approximated by a power-law equation (Atlas and Ulbrich, 1974):

$$
Q_{t}=a D^{n}
$$

where the coefficient $a$ and the exponent $n$ depend upon the wavelength and temperature. Using the above equation, the attenuation coefficient is given by

$$
k=c_{k}\left[\frac{a}{\Lambda^{n}}\right]\left[\frac{N_{0}}{\Lambda^{u}}\right] \frac{\Gamma(n+\mu+1)}{\Lambda}
$$

From $(7) .(8)$ and (10) we can deduce:

$$
\frac{Z}{k}=\frac{c_{z}}{c_{k}} \frac{\Gamma(7+\mu)}{\Gamma(n+\mu+1)} \frac{1}{a} \frac{D_{0}^{6 \cdots n}}{(3.67+\mu)^{6-n}}
$$

In the above equations, $c_{z}$ and $c_{k}$ are numerical constants and the equations have been written such that terms in brackets have rational dimensions (no fractional exponents of the length are involved). The values of the coefficients and the dimensions of the various terms are:

$$
\begin{gathered}
{[Z]=\left[\frac{m m^{6}}{m^{3}}\right],[k]=d B k m^{-1}} \\
{\left[\frac{1}{\Lambda}\right]=[c m],\left[\frac{a}{\Lambda^{n}}\right]=\left[c m^{2}\right],\left[\frac{N_{0}}{\Lambda^{\prime \prime}}\right]=\left[\mathrm{cm}^{-4}\right]} \\
{\left[D_{0}\right]=[c m],\left[N_{0} D^{\mu}\right]=\left[c m^{-4}\right]}
\end{gathered}
$$




$$
\begin{aligned}
& {\left[Q_{t}\right]=\left[\mathrm{cm}^{2}\right],[D]=[\mathrm{cm}]} \\
& c_{z}=10^{12}, c_{k}=4.343 \times 10^{5}
\end{aligned}
$$

The coefficient $a$ and the exponent $n$ in (9) are taken from Atlas and Ulbrich (1974, Table 1). For $3 \mathrm{~cm}$ wavelength, $\mathrm{a}=4.18$ to 13.24 and $\mathrm{n}=4.33$ to 5.16 for 0 to $40^{\circ} \mathrm{C}$

From (11), we see that for given $D_{0}$ and $\mu . \mathrm{Z}$ and $k$ are proportional to each other with a proportionality factor that depends upon the temperature through $a$ and $n$. Using (7). (8), and (10), we have prepared Fig. 12, which is a plot of $k$ vs $Z$ for four temperatures $(0,10,18$ and $40^{\circ} \mathrm{C}$ ), three median volume diameter, $D_{0}=1,2$ and $3 \mathrm{~mm}$, and three values of $\mu$, namely, $-2,0$ and 4 . Observed DSDs usually have $\mu$ in the range -2 to 3 and $N_{0}$ and $\mu$ are correlated. In preparing Fig. 12, it was not necessary to assume a value of $N_{0}$ because for a given $\mu$ and $D_{0}, Z$ determines $N_{0}$ (see (7) and (8)) and $k$ can then be calculated for any given temperature using (10). We see from (11), other factors being equal, increasing temperature generally gives greater $k$ because $a$ and $n$ in (9) increase with temperature; however, this trend is reversed when small drops predominate, that is, for small $D_{0}$. We see that, for a given $Z$, the median volume diameter, $D_{0}$. has a pronounced effect on $k$, a decreasc of $D_{0}$ results in a significant increase in k. The inferred attenuation coefficients, listed in Tables 2 and 3, are also plotted on Fig. 12 and will be discussed later. In this and subsequent figures, no attempt has been made to depict error bars for the probable uncertanties in the inferred $\mathrm{k}$; the lengths of the bars represent the range of reflectivities in the height interval. the ranges having been obtained from Figs. 16 and 18 to be discussed later.

2) Median Volume Diameter and Differential Reflectivity

The differential reflectivity (ZDR) is the ratio of the reflectivities at horizontal and vertical polarizations. Raindrop shapes are well approximated by ellipsoids of revolution with their axis ratios being a function of the drop volume. Using equations given in Seliga and Bringi 
(1976), and the raindrop axis ratio given by Andsager et al. (1999, Eq. 1), we have calculated and plotted ZDR in Fig. 13 as a function of $D_{0}$ for the gamma DSD for four values of $\mu$. A maximum drop diameter of $6 \mathrm{~mm}$ was assumed in the calculations. The range of median volume diameters plotted is limited by the range of slopes, $\Lambda$, considered to be acceptable, namely, 16 to $40 \mathrm{~cm}^{-1}$. We may note that, unlike $Z$ and $k$, both ZDR and $D_{0}$ are independent of $N_{0}$, the absolute magnitude of the DSD, and depend only on its shape. On this figure, we have also indicated the ranges of the observed ZDRs for the different height intervals for the two storms, The ZDRs were taken from Figs 16 and 18 presented later. Along the horizontal axis, the observed ZDRs have been positioned to intersect the curves for one or more values of $\mu$. These observational points will also be discussed later.

3) Reflectivity factor, Attenuation coefficient and Differential Reflectivity

Both variables, $Z$ and $k$, in Fig. 12 are proportional to $N_{0}$ [Eq. 8 and 9], while ZDR in Fig. 13 is independent of the magnitude of the DSD. Figure 12 can be used to estimate $D_{0}$ and $\mu$ of gamma DSDs that are consistent with the observed $Z$ and $k$. Figure 13 can be used to infer values of $D_{0}$ and $\mu$ of gamma DSDs that are consistent with the observed ZDRs. In the latter case, the magnitude of the distribution can then be inferred from the observed $Z$. However, Fig. 13 makes use only of the ZDR from the S-POL radar while Fig. 12 makes use of $Z$ and k: the results from the two need not agree. To use all the three measurables, namely, $Z, k$ and ZDR conveniently and consistently, we have constructed Fig. 14 which is a plot of $Z / k$ vs ZDR for $\mu=-2.0 .4$ and for temperature $=0,10,18,40^{\circ} \mathrm{C}$. Both $Z / k$ and ZDR are independent of $N_{0}$. However, together they make use of the three measurables, namely $Z$ and ZDR observed by the $S$-POL radar at the $10 \mathrm{~cm}$ wavelength, and $\mathrm{k}$ inferred from the $\mathrm{S}-\mathrm{POL}$ and EDOP reflectivities. It may be noted that Fig. 14 is not independent of Figs. 12 and 13 but a convenient combination of the tho figures that will facilitate our discussions. On Fig. 14. we have also plotted the 
observations for the Florida and Brazil storms: the Z/k and ZDR values are given in Tables 2 and 3.

\section{b. Vertical Doppler velocity and ZDR Structure of the Storms}

Vertical sections of the reflectivities of the two storms have been presented in Figs. 7, 9. 11 and 13. We now present additional observations of the storms to facilitate the later discussion of the inferred attenuation coefficients in the context of the vertical structure of the storms.

Figure 15 shows gray shade contour plots of (a) ZDR and (b) $V_{n}$, the Doppler velocity measured by the nadir-pointing beam of the EDOP radar, for the Florida storm. Contours of $Z_{s}$ have been superposed, and the dashed line shows the locus of minimum $V_{n}$. In Fig. 16, we show three vertical profiles of $Z_{s} . Z_{x n}, V_{n}$ and ZDR. The central plot is through the region of peak attenuation and the other two plots are $1 \mathrm{~km}$ on either side of it.

Figure 15 bhows that this storm has a sloping updraft (negative $V_{n}$ is directed upwards!. A maximum upward $V_{n}$ greater than $10 \mathrm{~ms}^{-1}$ occurs at a height of about $11 \mathrm{~km}$ at $66 \mathrm{~km}$ distance. This implics vertical air velocity greater than $10 \mathrm{~ms}^{-1}$ in that region since $V_{n}$ is the resultant of the vertical air velocity and the reflectivity-weighted fall velocity of the scatterers. In the vertical profiles we note a regular progression of the region aloft of $V_{12}<0$ in going from the left panel to the right panel which is a reflection of the sloping updraft. We note that below the melting level the $Z_{s}$ is practically constant (central panel, Fig. 16) except in the lowest levels. We also note that below the melting level, the ZDR contours slope in the same sense as the updraft. The ZDR increases downwards from about $1.7 \mathrm{~dB}$ at the melting level to about $3 \mathrm{~dB}$ at the $1 \mathrm{~km}$ level (see central panel. Fig. 16; we are concentrating on the central panel because it is the region through which attenuation was derived earlier); an exception occurs in the $1-2 \mathrm{~km}$ height interval in which the ZDR shows a small decrease downwards. 
Figures 17 and 18 for the Brazil storm are respectively similar to Figs. 15 and 16 for the Florida storm. This storm has a structure similar to that of the Florida storm but it is weaker as indicated by the reflectivities. The $V_{n}$ contours again show a well-developed sloping updraft. Upward Doppler velocity greater than $10 \mathrm{~ms}^{-1}$ occurs at about $10 \mathrm{~km}$ height and a distance of 33 $\mathrm{km}$, implying an updraft greater than $10 \mathrm{~ms}^{-1}$ in that region. We see again that below the melting level, the ZDR contours slope in the same sense as the $V_{n}^{\prime}$ contours aloft and $Z_{s}$ is again practically constant. The ZDRs below the melting level are smaller in this storm compared to the Florida storm implying that the drops in this storm were much smaller than the drops in the corresponding region of the Florida storm in keeping with the weaker character of the Brazil storm. In contrast to the Florida storm, the vertical profile of ZDR (central panel) shows that the ZDR was practically constant with height helow the melting level (excluding the lowest level where the data are questionable).

c. Inferences from the observed $Z, Z D R$ and $k$

1) Florida Storm:

From Fig. 12. we see that the observed $\mathrm{k}$ and $\mathrm{Z}$ for the $5-6 \mathrm{~km}$ (F5-6) height interval can only be explained in terms of a gamma rain DSD with $\mu=-2$ and a high $D_{0}$ of about $3 \mathrm{~mm}$ (Fig. 12a). On the other hand, the observed ZDR in Fig. 13 is consistent not only with a rain DSD with $\mu=-2$ and $D_{0}$ of about $3 \mathrm{~mm}$, but also with DSDs with $\mu=0$ and $D_{0}$ in the range 1.2 to $1.6 \mathrm{~mm}, \mu=2$ and $D_{0}$ in the range 1.4 to $1.9 \mathrm{~mm}$, and $\mu=4$ and $D_{0}$ in the range of about 1.9 to $2.1 \mathrm{~mm}$. None of the latter DSD parameters are consistent with $D_{0} \geq 3 \mathrm{~mm}$ suggested by Fig. 12. This is evident in Fig. 14 where here the observed $Z / k$ and ZDR for F5-6 are not consistent with any gamma DSD considered. The main reason for this inability to explain the observations in terms of a gamma rain DSD is that the inferred $k$ is too small for the observed $Z$. giving a large value of $Z / k$. In view of the fact that this height interval is mostly above the melting level $(4.8 \mathrm{~km})$, we conclude that this region was dominated by dry ice particles causing little 
attenuation. However, the observed ZDRs above the melting level $(0.3$ to $1.7 \mathrm{~dB}$ in the $5-7 \mathrm{~km}$ height interval) imply that super-cooled drops must have been present in that region. Microphysically, this is supported by the presence of a strong updraft in this region. Thus, we may conclude that super-cooled drops and ice co-existed in this region with the liquid drops providing the small attenuation that was observed.

The next lower height interval, F4-5 has its top near the melting level; therefore liqui drops and partially melted ice particles may be expected in this region. We see from Fig. 12 that the observed $Z$ and $\mathrm{k}$ are consistent with a gamma DSD with $\mu=-2$ and $D_{0}$ slightly greater than $1 \mathrm{~mm}$ (Fig. 12a), $\mu=0$ and $D_{0}$ slightly less than $2 \mathrm{~mm}$ (Fig. 12b), and a DSD with $\mu=4$ and a $D_{0}$ somewhat greater than $2 \mathrm{~mm}$ (Fig. 12c). From Fig. 13, we see that the observed ZDR is consistent with DSDs with $\mu=-2$ and $D_{0} \sim 1 \mathrm{~mm}, \mu=0$ and $D_{0} \sim 1.6$ to $2.0 \mathrm{~mm} . \mu=2$ and $D_{0} \sim 2$ to $2.4 \mathrm{~mm}$ : and $\mu=4$ and $D_{0} \sim 2.2$ to $2.6 \mathrm{~mm}$. However, Fig. 14 shows that the observed $\mathrm{Z} / \mathrm{k}$ and ZDR are not consistent with any of the gamma DSDs considered. This is because the $\mathrm{k}$ is too high for a gamma distribution with the observed $Z$, giving a point that lies below the curves in Fig. 14. We conclude that this layer contained a mixture of water drops and watercoated ice particles formed by the partial melting of ice particles falling across the 0 "C level.

Similar to F4-5, the observed points for F3-4 and F!-2 lie below all the curves in Fig. 14 . The attenuation is too large again to be due to a gamma DSD. Therefore, we conclude that these regions also contained partially melted ice particles that contributed to the high attenuation. It is important to note that if only some of the observations such as $Z$ and ZDR had been considered. the observations would be falsely interpreted in terms of a gamma DSD. The additional information provided by the X-band observations, through the inferred attenuation, strongly suggests that mixed phase particles, rather than just water drops, were present in this region.

Our hypothesis of melting particles is also supported by the systematic increase in ZDR with decreasing altitude as seen in the vertical section and profile of ZDR (Figs. 15 and 16) as 
well as Fig. 14. The observed increase in Z.DR implies a substantial increase in the mean drop size with decreasing altitude. If only raindrops had been present, the observed increase in mean drop size could not be explained because the evolution of rain DSD by coalescence, which tends to increase the drop size. is very small and is counteracted by drop breakup. We believe that the observed increase in ZDR could be due to the formation of larger drops through the melting of larger ice particles with distance down. However, this hypothesis needs to be tested through microphysical calculations of the melting of ice particles; this task is left for the future.

We assumed that partially water-coated ice particles provided the observed high attenuation. This is supported by earlicr work (Battan and Herman 1962). We have calculated the extinction cross-section of melting spherical ice particles in which the melt is assumed to form a concentric water coat. This is obviously a simplification, because the coat may be eccentric, the ice core may be not spherical, and the melted water may soak inside the particle, especially in the case of a particle of low bulk density. However, the simplified calculations should provide a qualitative guide. Fig. 19 shows the normalized extinction cross-section as a function of the fraction of mass melted for several values of the melted diameter and three values of bulk ice density. The extinction cross-section is normalized by the geometric cross-section of the melted particle. We see that the extinction cross-section of the partially melted particle can easily exceed that of the melted particle for certain sizes and melt fractions by a factor of several. The effect could be larger for deformed particles (Atlas et al. 1953).

2) Brazil Storm

The results for this storm are very similar to those for the Florida storm. From Fig. 12. we see that for the $4-5 \mathrm{~km}$ height interval (B4-5) which straddles the melting level at $4.2 \mathrm{~km}$ AGL, the observed $Z$ and $k$ are explainable by a gamma rain DSD with $\mu=-2$ and a large $D_{0}$ of about $3 \mathrm{~mm}$ (Fig. 12a). This high $D_{0}$ is inconsistent with the observed ZDR: according to Fig. 13. the ZDR could be due to gamma DSDs with $\mu=-2$ and $D_{0}=1 \mathrm{~mm}, \mu=0$ and $D_{0}=1.5 \mathrm{~mm}$. $\mu=$ 
2 and $D_{0}=1.8 \mathrm{~mm}$, and $\mu=4$ and $D_{0}=2 \mathrm{~mm}$. This inconsistency between Figs. 12 and 13 is also evident in Fig. 14, which shows that the $\mathrm{Z} / \mathrm{k}$ lies above all the points considered. We again attribute this to a small attenuation because of the predominance of dry ice particles above the melting level. However. the observed ZDR $(\sim 1.5 \mathrm{~dB})$ again suggests that some super-cooled drops were present; these drops account for the small attenuation that was inferred. Again, the presence of a strong updraft in this region supports the hypothesis of liquid drops above the freezing level. We note the interesting and perhaps significant fact that for both storms, the points representing the layers immediately above the respective melting levels occupy very similar positions on the diagram of Fig. 14.

The observations for the lower layers, B3-4 and B2-3, are very similar to the observations in the Florida storm below the melting level. Similar to the discussion to the Florida storm. for Figs. 12 and 13, two of the three parameters, $Z, k$ and ZDR can be used to select the parameters of a gamma DSD that fits the observations. However, Fig. 14 again shows that the Zik points lie below all the gamma DSDs considered. This implies a $k$ too high for the observed $Z$ to be explained by a gamma DSD. As in the case of the Florida storm, we conclude that liquid drops and partially melted. water-coated, ice particles were responsible for the high altenuation.

The ZDR was nearly constant below the melting level in contrast to the Florida storm. which showed a systematic and considerable increase with decreasing altitude. The ZDRs for the Brazil storm are also considerably smaller than for the Florida storm. This implies that the Brazil storm had smaller particles. This is consistent with the lower intensity of the Brazil storm.

\section{Summary and Concluding Remarks}

Observations by the EDOP (NASA's ER-2 Doppler) radar, which operates at $3.2 \mathrm{cin}$ wavelength and makes observations in a nadir and a $33^{\circ}$ forward-pointing beam, show that over land the surface cross-section is highly variable at nadir incidence but is stable to within 1-2 dB at the forward incidence. There was no evidence of changes in the surface cross-section before 
entering and after exiting regions of heavy precipitation. Thus, measurement by the forward beam provides a viable method for measuring PIA (path integrated attenuation) by the SRT (surface reference technique) over land. Observations over land in a number of deep convective storms in Florida and Brazil yielded PIAs exceeding $20 \mathrm{~dB}$ between storm top and surface. We selected two storms, one in Brazil and one in Florida, for detailed study using the EDOP and SPOL (NCAR S-band Polarization) radar data.

The PIA between storm top and 'surface' was also estimated by the dual-wavelength method using the S-POL (S-band) and EDOP (X-band) reflectivities. In addition, the dual wavelength method was used to estimate range-resolved specific attenuation using the S-band radar data and the EDOP radar data from the nadir beam. Very good agreement was found between the forward beam PIA from the SRT and the dual wavelength method for the Florida storm: the agreement was not as good for the Brazil storm. The PIA was aiso calculated by integrating an empirical equation relating attenuation coefficient and reflectivity ( $\mathrm{S}$ band) for rain DSDs (drop size distributions). It was found that the PIA so deduced and the PIA found by the SRT had very similar shapes though they differed in magnitude: the two PIAs could probably be made to agree quite well by 'tuning' the coefficient and exponent in the empirical attenuationreflectivity equation. However, this tuning procedure has no physical basis as shown by the inferences from the dual-wavelength data and the observed differential reflectivities.

Both storms showed small attenuation above the melting level and significant ZDRs in layers a few kilometers thick lying just above the melting level. We concluded that this region was dominated by dry ice particles, but had coexisting supercooled drops in order to account for the observed ZDRs. The existence of supercooled drops is also supported by the Doppler velocity observed by the nadir beam of EDOP. The Doppler velocities showed strong sloping updrafts above the melting level. 
Below the melting level, rather large specific attenuations were deduced by the dualwavelength method. Theoretical relationships between the attenuation coefficient, reflectivity and ZDR for a gamma rain DSD were formulated and discussed at length in an attempt to interpret the observations in terms of gamma rain DSD. It was possible to explain the observations in certain height intervals by means of a gamma rain DSD and deduce its parameters if only two of the three parameters were considered. However, such interpretation was found inconsistent with all three parameters mainly because the inferred attenuation, beiow the melting level, was too large for the observed $\mathrm{Z}$. We also found a marked and systematic increase in ZDR with decreasing altitude, in the Florida storm, that can not be accounted for by the evolution of a rain DSD. It was suggested that the large attenuation was due to partially melted water-coated ice particles that present a larger extinction cross-section than the completely melted particle. Calculations for spherical water coated particle showed that the gain in extinction could be quite pronounced for ice particles of low bulk density. It is also known that deformed particles can cause even more extinction. The Florida storm was more intense than the Brazil storm as suggested by its higher reflectivity. It contained bigger particles. as suggested by larger ZDRs; the larger ice particles required longer fall paths for complete melting and wera probably responsible for the observed downward increase of ZDR.

This study has shown the benefit of combining $\mathrm{X}$-band airborne radar observation and $\mathrm{S}$ band polarmetric measurements, i.e., a dual-wavelength method, for the study of microphysics of convective storms. Earlier attempts at using dual-wavelength method for ground-based measurements have used collocated radars, or common antennas with the matched beamwidth: to overcome problems anticipated from lack of coincidence of radar resolution volumes. However, those methods usually yield the attenuation along horizontal paths. For dee? convective storms, the structure along a vertical path is of paramount interest. Our study has shown that the combination of a down looking short wavelength (Doppler) radar and a ground- 
based S-band polarimetric radar can be used to infer plausible attenuation coefficients in deep convective storms. Valuable inferences about storm microphysics can be drawn by combining resulting dual-wavelength and ground-based polarimetric data. Such studies are important in order to improve the SRT approach over land for TRMM future satellite and to provide a firmer physical basis for its use. With proper design of scan strategies to obtain optimum space-time coincidence between ground-based and airborne radar data sets, it should be possible to obtairi more accurate results. The interpretation of dual wavelength reflectivity, polarimetric, and Doppler velocity observations needs to be supported by further studies of the characteristics of melting particles, in particular, their radar and extinction cross-sections.

\section{Acknowledgments}

The authors thank Dr. J. Vivekanandan and Art Jameson for their interest and helpful dissuasions. We appreciate Dr. Steve Bidwell and Ed Zenker for their engineering support. We also thank Bob Rilling for providing S-Pol data. This work is supported by Dr. R. Kakar of NASA Headquarters under NASA's Tropical Rainfall Measuring Mission 621-15-46. The work

of Ramesh C. Srivastava in TRMM is supported by NASA NAG 54777.

\section{References}

Andsager, Karen, Kenneth V Beard. Neil F. Laird, 1999: Laboratory measurements of axis ratios for large raindrops. J. Atmos. Sci. 56, 2673-2683.

Atlas, D., and Banks, 1951: The interpretation of microwave reflections from rainfall. J. Meteor. $8,271-282$.

, and C. W. Ulbrich, 1974: The physical basis for attenuation-rainfall relationships and the measurement of the rainfall parameters by combined attenuation and rainfall methods. $J$. Rech. Atmos., 8, 175-298.

. Kerker. M., and Hitschfeld. W.. 1953: Scattering and attenuation by non-spherical atmospheric particles. J. Atmos. Terrest. Phys. 3. 108-119. 
Battan, L.. 1973: Radar Observation of the Atmosphere. University of Chicago Press, 324 pp.

Battern, L. J., and Herman, B. M.. 1962: The radar cross section of "spongy" ice spheres. J. Geophys. Res., 67, 5139-5145.

Bolen, M. S., and V. Chandrasekar, 2000: Quantitative cross validation of space-based and ground-based radar observations. J. Appl. Meteor., 39, 2071-2079.

Doviak, R. J., and D. S.Znic, 1993: Doppler Radar and Weather Observations. $2^{\text {nd }}$ ed. Academic Press. 565 pp.

Eccles, P.J.. and E. A. Muller, 1971: X-band attenuation and liquid water content estimation by dual-wavelength radar. J. Appl. Meteor., 10, 1252-1259.

Heymsfield, G.M., S.W. Bidwell, I.J.Caylor, S. Ameen, S. Nicholson, W. Boncyk, L. Miller, D. Vandemark. P.E. Racette, and L.R. Dodd,1996: The EDOP radar system on the high-altitude NASA ER-2 aircraft. J. Atmos. Oceanic Technol., 13. 795-809.

Iguchi, T. Kozu, R. Meneghini, J. Awaka, and K. Okamoto, 2000: Rain-profiling algorithm for the TRMM precipitation radar. J. Appl. Meteor., 39, 2038-2052.

Kummerow, C.. W. Barnes. T. Kozu, J. Shiue, and J. Simpson, 1998: The Tropical Rainfall Measuring Mission (TRMM) sensor package. J. Ammos. Oceanic Technol. 15, 809-817.

Meneghini, R.. J. Eckerman. and D. Atlas: 1983: Determination of rain rate from a spaceborne radar using measurements of total attenuation. IEEE Trans. Geosci. Remote Sensing. GE-21, N0. $1,34-43$.

T. Iguchi, T. Kozu, L. Liao, K. Okamoto, J. Aones, and J. Kwiakowski. 2000: Live of the surface reference technique for path attenuation estimates from the TRMM Precipitation Radar. J. Appl. Meteor. 39. 2053-2070

Seliga. T. A.. and Bringi. V. N. 1976: Potential use of radar differential reflectivity measurements at orthogonal polarizations for measuring precipitations. J. Appl. Mcteorol.. $15,69-76$. 
Srivastava, R. C. and L. Tian, 1996: Attenuation by a dual-radar method: Concept and error analysis. J. Atmos. Oceanic Technol., 13, 937-947.

Testude, J., and P. Amayenc, 1989: Stereoradar meteorology: A promising method to observe precipitation from a mobil platform. J. Atmos. Oceanic Technol., 6, 89-108.

Tian, L., and R. C. Srivastava, 1997: Measurement of attenuation at C band in a convective storm by a dual-radar method, J. Atmos. Oceanic Technol., 14, 184-196.

Ulaby, F. T., R. K. Moore, and A. K. Fung, 1982: Microwave Remote Sensing: Active and Passive. Vol. 2. Addison-Wesley, 607 pp.

Ulbrich, C. W., 1983: Natural Variation in the analytical form of the rain drop size distribution. J. Climate and App. Meteoro., 22, 1764-1983. 


\section{FIGURE LEGENDS}

Figure 1. Histogram of surface scattering cross-section over (a) ocean and (b) land at forward (solid) and nadir (dashed) incidence observed by the EDOP radar. $20 \mathrm{~dB}$ are added to forward surface cross-section for display purpose.

Figure 2. Vertical cross-section of reflectivity at (a) nadir and (b) forward incidence, and (c) surface cross-section for forward (solid) and nadir (dashed) beams observed by EDOP radar on 12 February, 1999 in Ji Parna Brazil.

Figure 3. Reflectivity at S-band (solid), X-band (short dashes) and their difference (long dashes) for mono-disperse distributions of spherical raindrops as a function of drop diameter.

Figure 4. Constant altitude, $8 \mathrm{~km}$ agl, contour maps of (a) reflectivity, (b) differential reflectivity, ZDR, and (c) linear depolarization ratio, LDR in a storm in Florida on 15 August 1998, 2224-2227 UTC reconstructed from S-POL radar data. The location of maximum reflectivity is marked by + and the projection of the flight path of the airborne EDOP radar is shown by the line.

Figure 5. Vertical cross-sections corresponding to Fig. 4 for the Florida storm. (a) reflectivity, $Z_{s}$, from S-POL radar, (b) forward beam reflectivity, $Z_{x:}$, from EDOP radar, and (c) path integrated attenuation. PIA, deduced using the surface reference technique (SRT. solid), integration of empirical equation 4 (dotted) and the dual wavelength method (dashed). 
Figure 6. Scatter plots of S-band reflectivity, $Z_{s}$, against $\mathrm{X}$-band reflectivities at incidence for the Florida storm. The one-to-one lines are also shown.

Figure 7. Plots for the Florida storm. for the heights (AGL) of 1.0. 2.0, 3.0, 4.0, 5.0 and 6 $\mathrm{km}$ : (a) S-band reflectivity, $Z_{s}$ (b) difference of S-band and nadir beam X-band reflectivity, $Z_{s}-Z_{x n}$ and (c) PIA from integration of empirical equation 4 along the nadir beam. Vertical line in the plot indicates the distance at which the maximum attenuation occurs. For details see text.

Figure 8. Constant altitude, $3 \mathrm{~km}$ agl, contour map of reflectivity for a storm in Brazil on 10 February 1999, 1810-1815 UTC, reconstructed from S-POL radar data. The location of maximum reflectivity is marked by + and the projection of the flight path of the airborne EDOP radar is shown by the line.

Fig. 9. Similar to Fig. 5 but for the Brazil storm.

Fig. 10. Similar to Fig. 6 but for the Brazil storm.

Fig. 11. Similar to Fig. 7 but for the Brazil storm.

Fig. 12. Specific attenuation at $3 \mathrm{~cm}$ wavelength versus reflectivity at $10 \mathrm{~cm}$ wavelength for gamma function drop size distribution with shape parameters of (a) $\mu=-2$. (b) $\mu=0$, and (c) $\mu=4$. for median volume diameters $D_{0}=1,2,3 \mathrm{~mm}$ and temperatures of $0,10,1820^{\circ} \mathrm{C}$. The inferred specific attenuations and reflectivity along the vertical line in 
Fig. 7 for the Florida and Brazil are also plotted against reflectivity observed by the SPOL radar with symbols $\mathrm{Fx}$ and $\mathrm{Bx}$ where $\mathrm{x}$ denote the layer interval in $\mathrm{km}$.

Fig. 13. Differential reflectivity, ZDR, against median volume diameter for $\mu=-2,0,2,4$ for the gamma drop size distribution. The range of median volume diameters plotted is limited by the range of slopes considered, namely, 16 to $40 \mathrm{~cm}^{-1}$. Fx and Bx specify the Florida and Brazil storms, respectively, where $x$ denote the layer interval in $\mathrm{km}$. For details, see text.

Fig. 14. Plot of $Z_{s} / k$ versus ZDR for gamma rain DSD for (a) $\mu=-2$, (b) $\mu=0$ and (c) $\mu=2$, for four temperatures. The observed 'points' are also depicted on the figures. Fx and $\mathrm{B} x$ specify the Florida and Brazil storms, respectively, where $x$ denotes the layer interval in $\mathrm{km}$. For details, see text.

Fig. 15. Vertical cross-sections of (al) differential reflectivity and (b) nadir beam Doppler velocity for the Florida storm. S-band reflectivity contours are also shown. The melting level is indicated by dotted line.

Fig. 16. Vertical profiles of S-band reflectivity (solid), X-band nadir beam reflectivity (dashes), X-band nadir beam Doppler velocity (dash-dot), and differential reflectivity (dotted) for the Florida storm. The central plot is through the region of maximum path integrated attenuation. the left plot is $1 \mathrm{~km}$ left of it, and the right plot is $1 \mathrm{~km}$ to the right of it.

Fig. 17. Similar to Fig. 15, for the Brazil storm. 
Fig. 18. Similar to Fig. 16, for the Brazil storm.

Fig. 19. Normalized extinction cross-section of melting ice particles versus fraction of mass melted for selected melted diameters of $3,4,6,7,8$, and $10 \mathrm{~mm}$ and three bulk densities of ice: a) 0.3 b) 0.5 and c) $0.92 \mathrm{~g} \mathrm{~cm}^{-3}$. The ice particle is assumed to be spherical and melt is assumed to form a concentric sphere coat around it. The normalization is performed by the cross-section of the completely melted particle. Calculations are based on Mie theory. 


\section{LIST OF TABLES}

Table 1. List of EDOP flight legs with PIA larger than $20 \mathrm{~dB}$.

Table 2: Summary of inferred attenuation and other parameters for Florida storm, 10 August, 1998. The values in the last four columns are for the height intervals in $3^{\text {ri }}$ column.

Table 3: Summary of inferred attenuation and other parameters for Brazil storm, 10 February 1999. The values in the last four columns are for the height intervals in $3^{\text {rd }}$ column. 
Table 1. List of EDOP flight legs with PIA larger than $20 \mathrm{~dB}$.

\begin{tabular}{|c|c|c|c|c|}
\hline Day & Time & Location & Max. PIA (dB) & cloud top $(\mathrm{km})$ \\
\hline 980815 & $2223-2237$ & Florida & 30 & 18 \\
\hline 980905 & $2217-2221$ & Florida & 25 & 16 \\
\hline 990125 & $2215-2223$ & Brazil & 29 & 16 \\
\hline 990125 & $2242-2246$ & Brazil & 30 & 16 \\
\hline 990120 & $1810-1815$ & Brazil & 29 & 15 \\
\hline 990212 & $1955-2000$ & Brazil & 20 & 13 \\
\hline 990212 & $2049-2055$ & Brazil & 15 & 14 \\
\hline 990217 & $1846-1859$ & Brazil & 23 & 13 \\
\hline
\end{tabular}


Table 2: Summary of inferred attenuation and other parameters for Florida storm, 10 August. 1998. The values in the last four columns are for the height intervals in $3^{\text {rd }}$ column.

\begin{tabular}{|l|l|l|l|l|l|l|}
\hline $\begin{array}{l}\text { Height }(\mathrm{km}) \\
\text { From top to }\end{array}$ & $\begin{array}{l}\text { Two-way } \\
\text { PIA }(\mathrm{dB})\end{array}$ & $\begin{array}{l}\text { Height } \\
\text { Interval } \\
(\mathrm{km})\end{array}$ & $\begin{array}{l}\text { One-way } \\
\text { attenuation } \\
(\mathrm{dB} \mathrm{km})\end{array}$ & $Z_{s}(\mathrm{dBZ})$ & $\mathrm{ZDR}(\mathrm{dB})$ & $\mathrm{Z} / \mathrm{k}$ \\
\hline 1 & 33 & & & & & \\
\hline 2 & 24 & $1-2$ & 4.5 & -51 & $2.5-3.0$ & $2.8 \times 10^{4}$ \\
\hline 3 & 19 & $2-3$ & 2.5 & $52-53$ & $2.7-2.5$ & $(6.3-8) \times 10^{4}$ \\
\hline 4 & 9 & $3-4$ & 5.0 & -52 & $2.2-2.7$ & $3.2 \times 10^{4}$ \\
\hline 5 & 2 & $4-5$ & 3.5 & -52 & $1.7-2.2$ & $4.5 \times 10^{4}$ \\
\hline 6 & 0.5 & $5-6$ & 0.75 & $-50-52$ & $1.0-1.7$ & $(1.3-2.1) \times 10^{5}$ \\
\hline & & $6-t o p$ & $0.25 \mathrm{~dB}$ & $-49-51$ & & \\
\hline
\end{tabular}


Table 3: Summary of inferred attenuation and other parameters for Brazil storm, 10 February 1999. The values in the last four columns are for the height intervals in $3^{\text {rd }}$ column.

\begin{tabular}{|l|l|l|l|l|l|l|}
\hline $\begin{array}{l}\text { Height }(\mathrm{km}) \\
\text { From top to }\end{array}$ & $\begin{array}{l}\text { Two-way } \\
\text { PIA }(\mathrm{dB})\end{array}$ & $\begin{array}{l}\text { Height } \\
\text { Interval } \\
(\mathrm{km})\end{array}$ & $\begin{array}{l}\text { One-way } \\
\text { attenuation } \\
(\mathrm{dB} \mathrm{km})^{-1}\end{array}$ & $Z_{s}(\mathrm{dBZ})$ & $\mathrm{ZDR}(\mathrm{dB})$ & $\mathrm{Z} / \mathrm{k}$ \\
\hline 1.5 & 21 & & & & & \\
\hline 2 & 23 & $1.5-2$ & -2.0 & $40-50$ & $1.7-0.8$ & \\
\hline 3 & 16 & $2-3$ & 3.5 & $\sim 49$ & $1.6-1.7$ & $2.3 \times 10^{4}$ \\
\hline 4 & 6 & $3-4$ & 5.0 & $\sim 57$ & $1.6-1.7$ & $2.5 \times 10^{+}$ \\
\hline 5 & 5 & $4-5$ & 0.5 & $\sim 51$ & 1.5 & $2.5 \times 10^{5}$ \\
\hline 6 & $?$ & $5-6$ & $?$ & $\sim 50$ & $1.3-1.5$ & \\
\hline
\end{tabular}



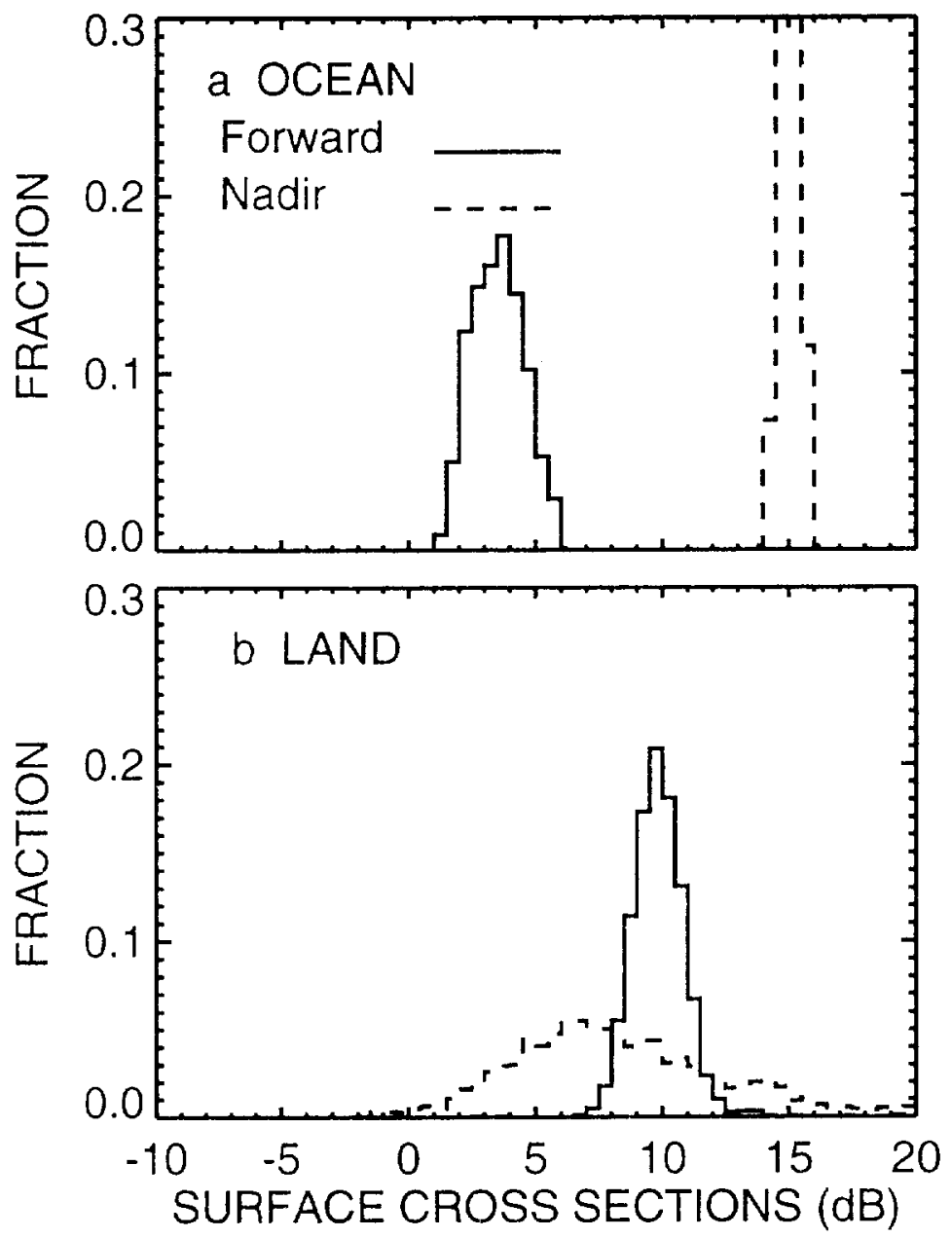

Figure 1. Histogram of surface scattering cross-section over (a) ocean and (b) land at forward (solid) and nadir (dashed) incidence observed by the EDOP radar. $20 \mathrm{~dB}$ are added to forward surface cross-section for display purpose. 


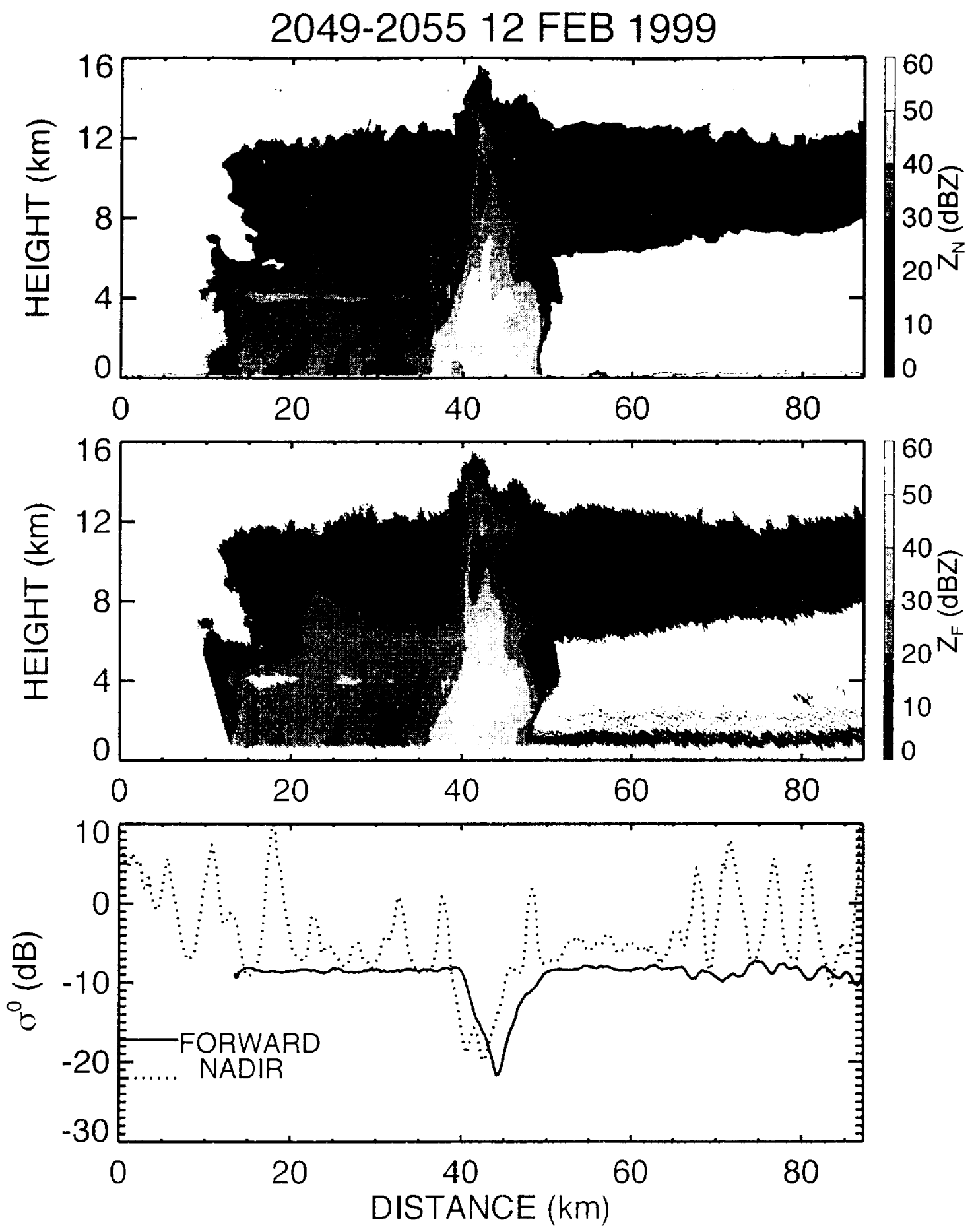

Figure 2. Vertical cross-section of reflectivity at (a) nadir and (b) forward incidence, and (c) surface cross-section for forward (solid) and nadir (dashed) beams observed by EDOP radar on 12 February. 1999 in Ji Parna Brazil. 


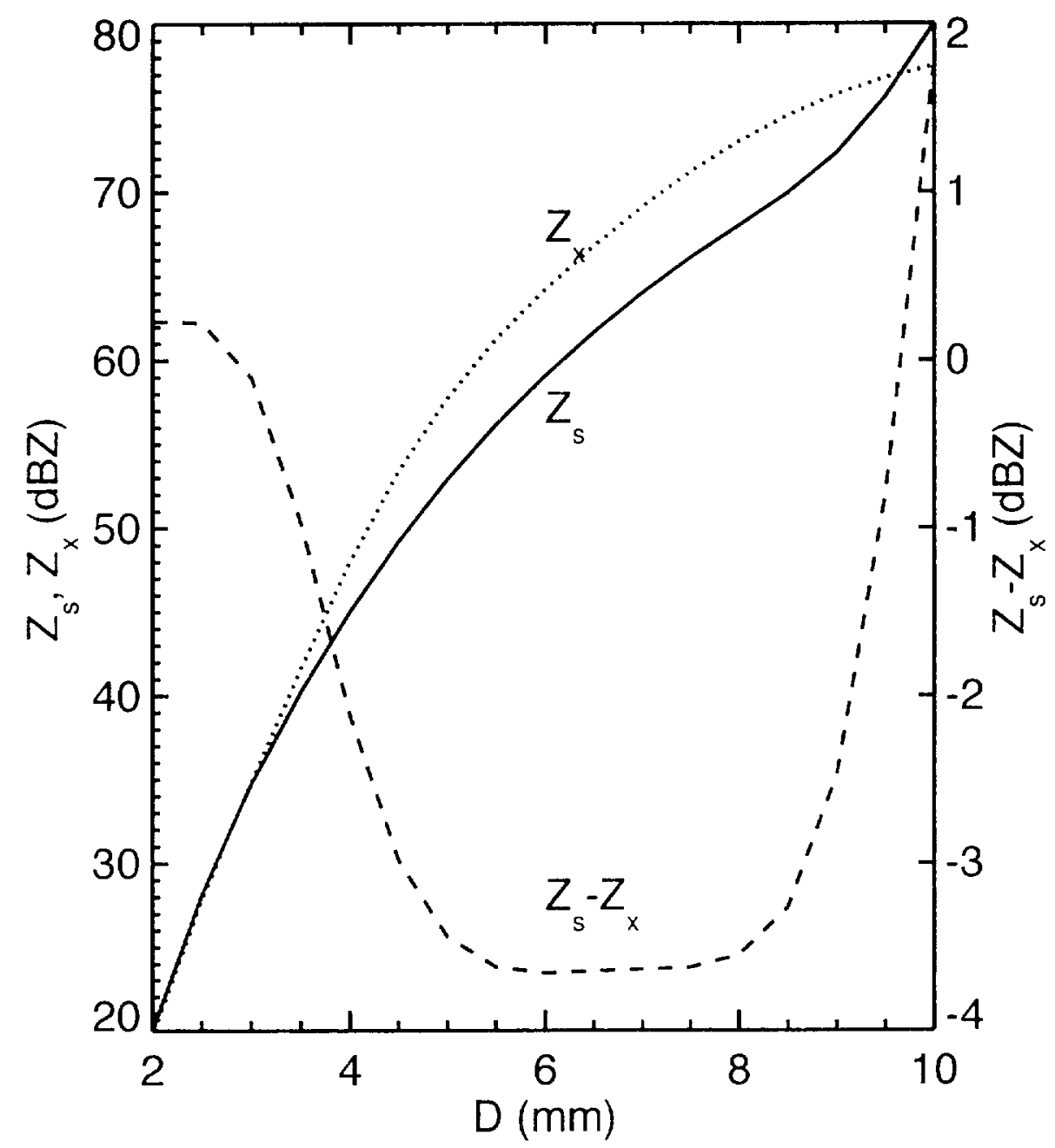

Figure 3. Reflectivity at S-band (solid), X-band (short dashes) and their difference (long dashes) for mono-disperse distributions of spherical raindrops as a function of drop diameter. 


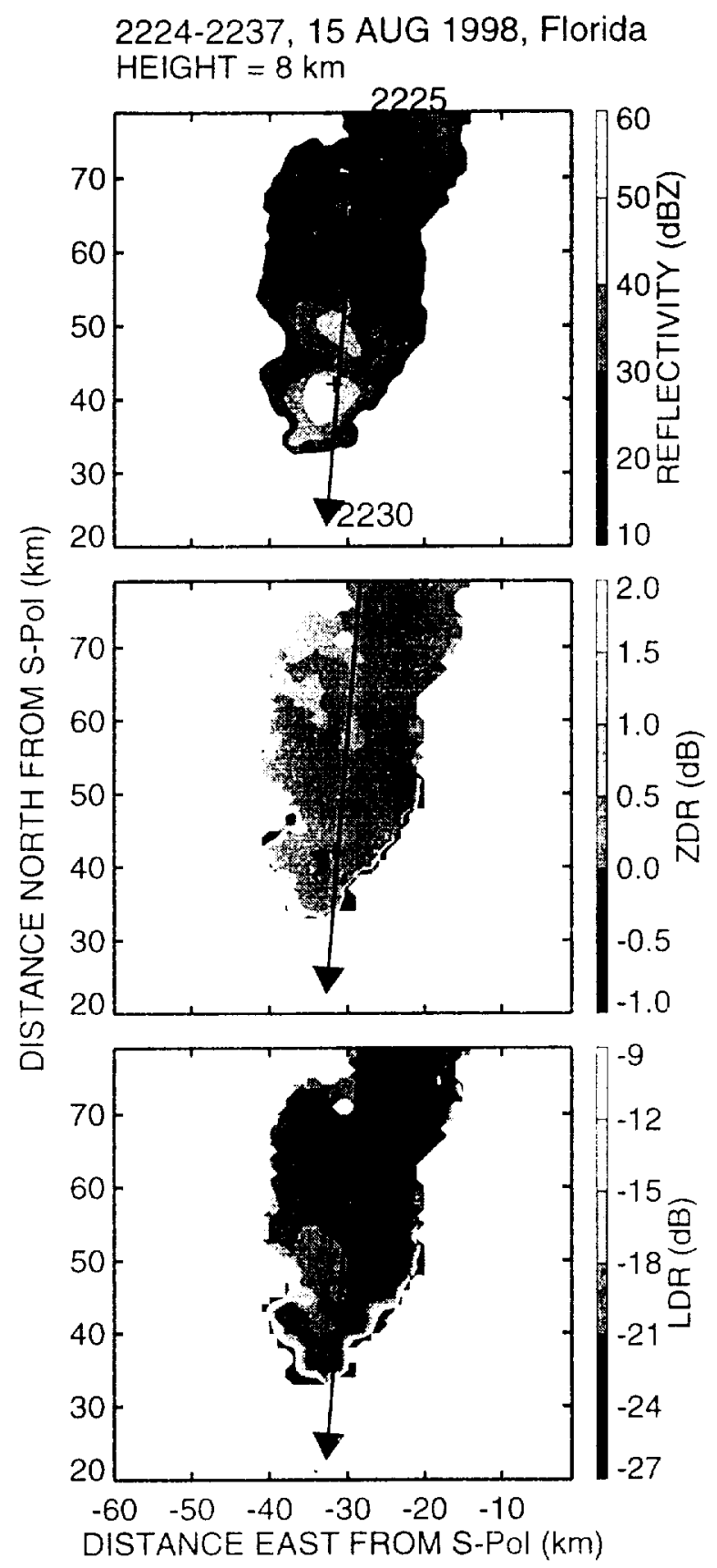

Figure 4. Constant altitude, $8 \mathrm{~km}$ agl, contour maps of (a) reflectivity, (b) differential reflectivity, ZDR, and (c) linear depolarization ratio, LDR in a storm in Florida on 15 August 1998, 2224-2227 UTC reconstructed from S-POL radar data. The location of maximum reflectivity is marked by + and the projection of the flight path of the airborne EDOP radar is shown by the line. 

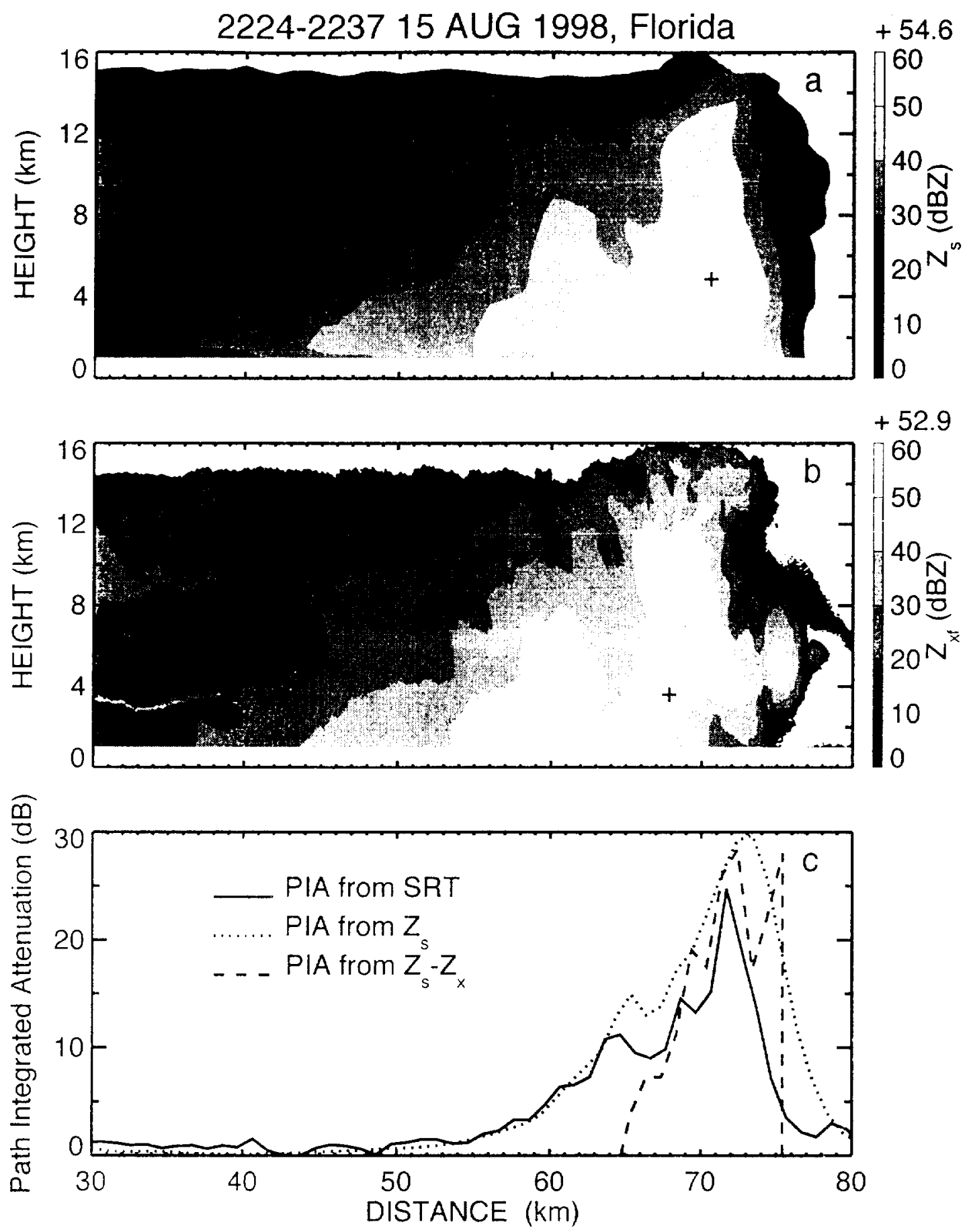

Figure 5. Vertical cross-sections corresponding to Fig. 4 for the Florida storm. (a) reflectivity $Z_{s}$, from $S$-POL radar, (b) forward beam reflectivity, $Z_{x i}$, from EDOP radar, and (c) path integrated attenuation, PIA, deduced using the surface reference technique (SRT. solid), integration of empirical equation 4 (dotted) and the dual wavelength method (dashed). 


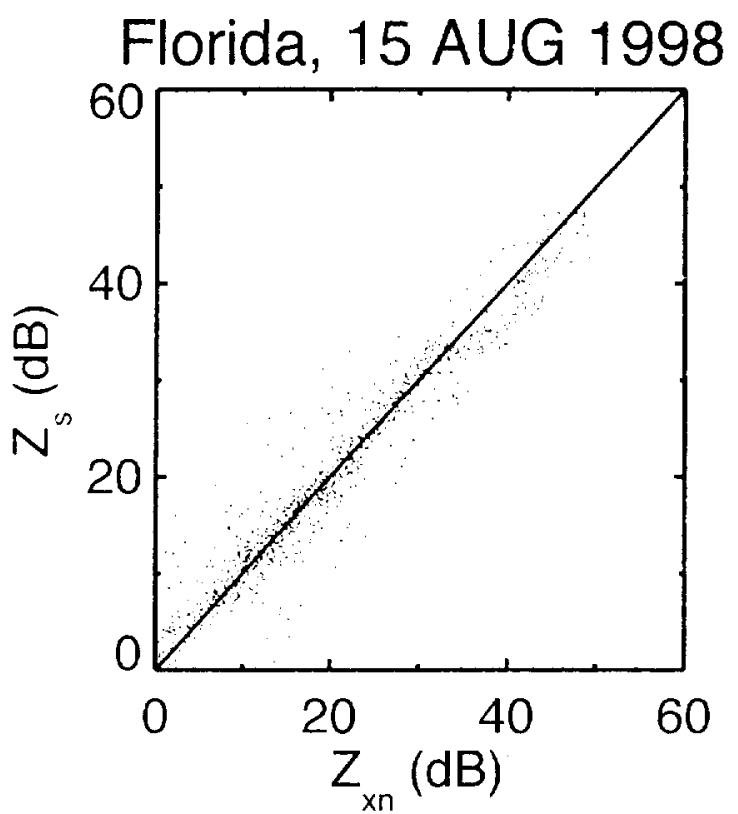

Figure 6. Scatter plots of $S$-band reflectivity, $Z_{s}$, against $\mathrm{X}$-band reflectivities at incidence for the Florida storm. The one-to-one lines are also shown. 

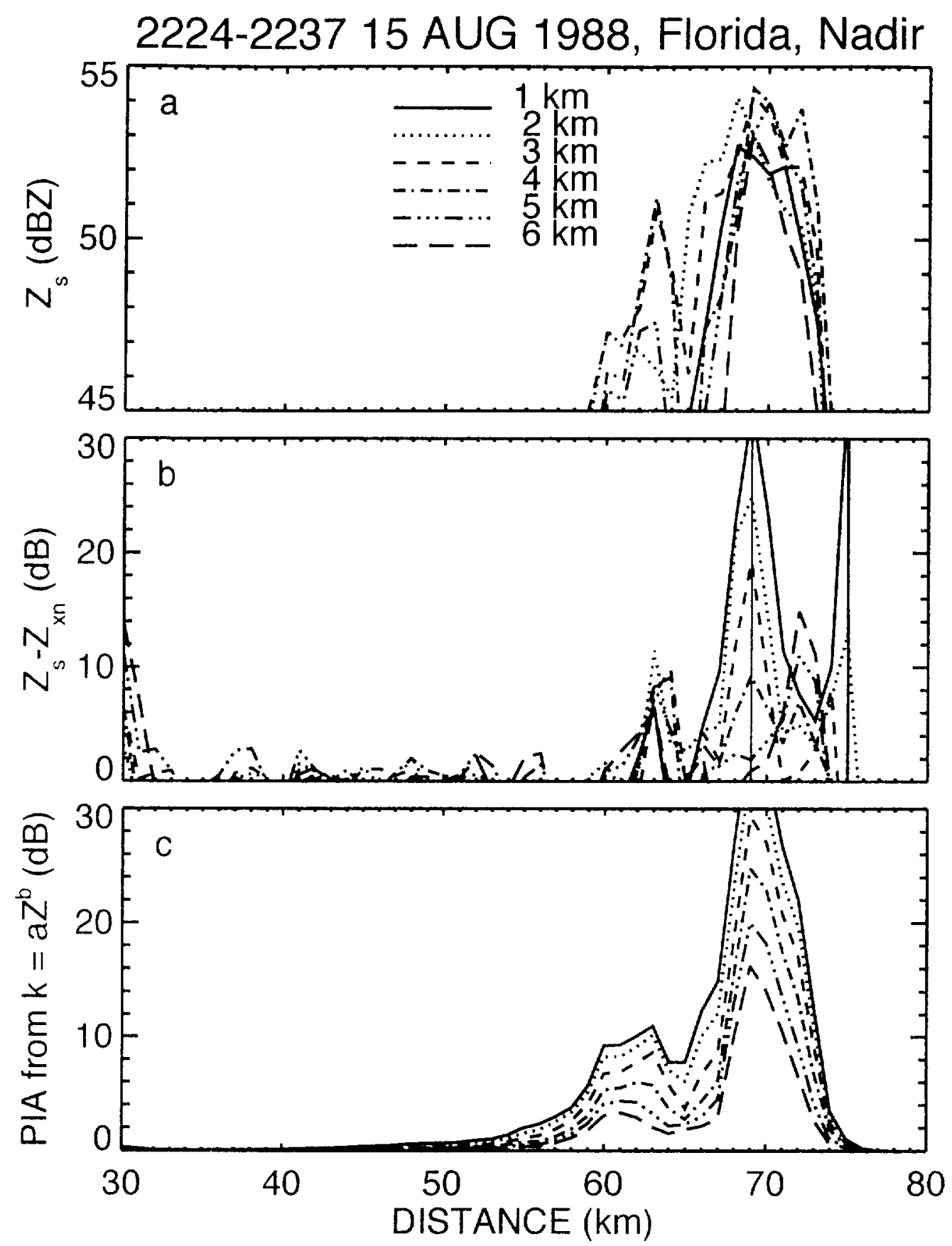

Figure 7. Plots for the Florida storm, for the heights (AGL) of 1.0, 2.0, 3.0, 4.0, 5.0 and 6 $\mathrm{km}$ : (a) S-band reflectivity, $Z_{s}$ (b) difference of $S$-band and nadir beam X-band reflectivity. $Z_{s}-Z_{s n}$ and (c) PIA from integration of empirical equation 4 along the nadir beam. Vertical line in the plot indicates the distance at which the maximum attenuation occurs. For details see text. 


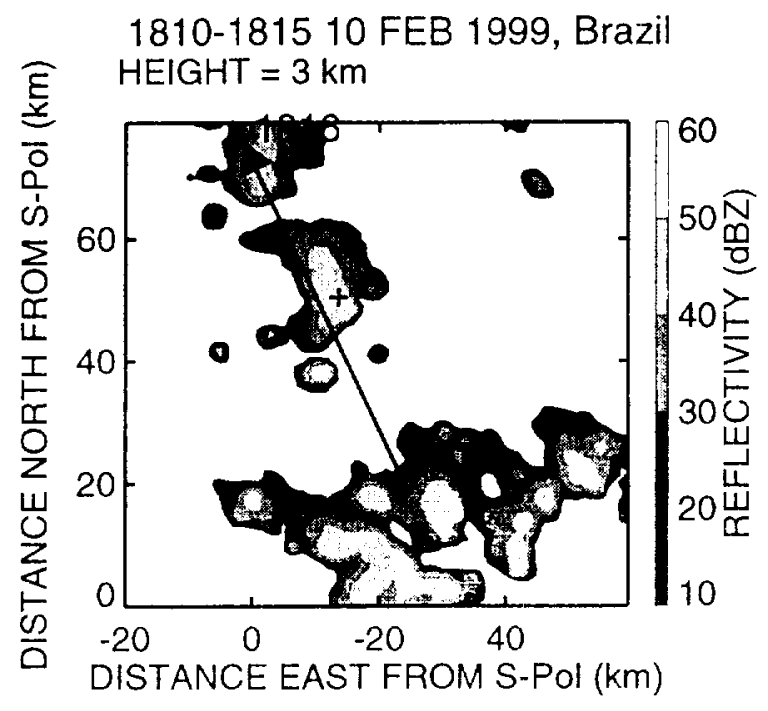

Figure 8 . Constant altitude, $3 \mathrm{~km}$ agl, contour map of reflectivity for a storm in Brazil on 10 February 1999, 1810-1815 UTC, reconstructed from S-POL radar data. The location of maximum reflectivity is marked by + and the projection of the flight path of the airborne EDOP radar is shown by the line. 

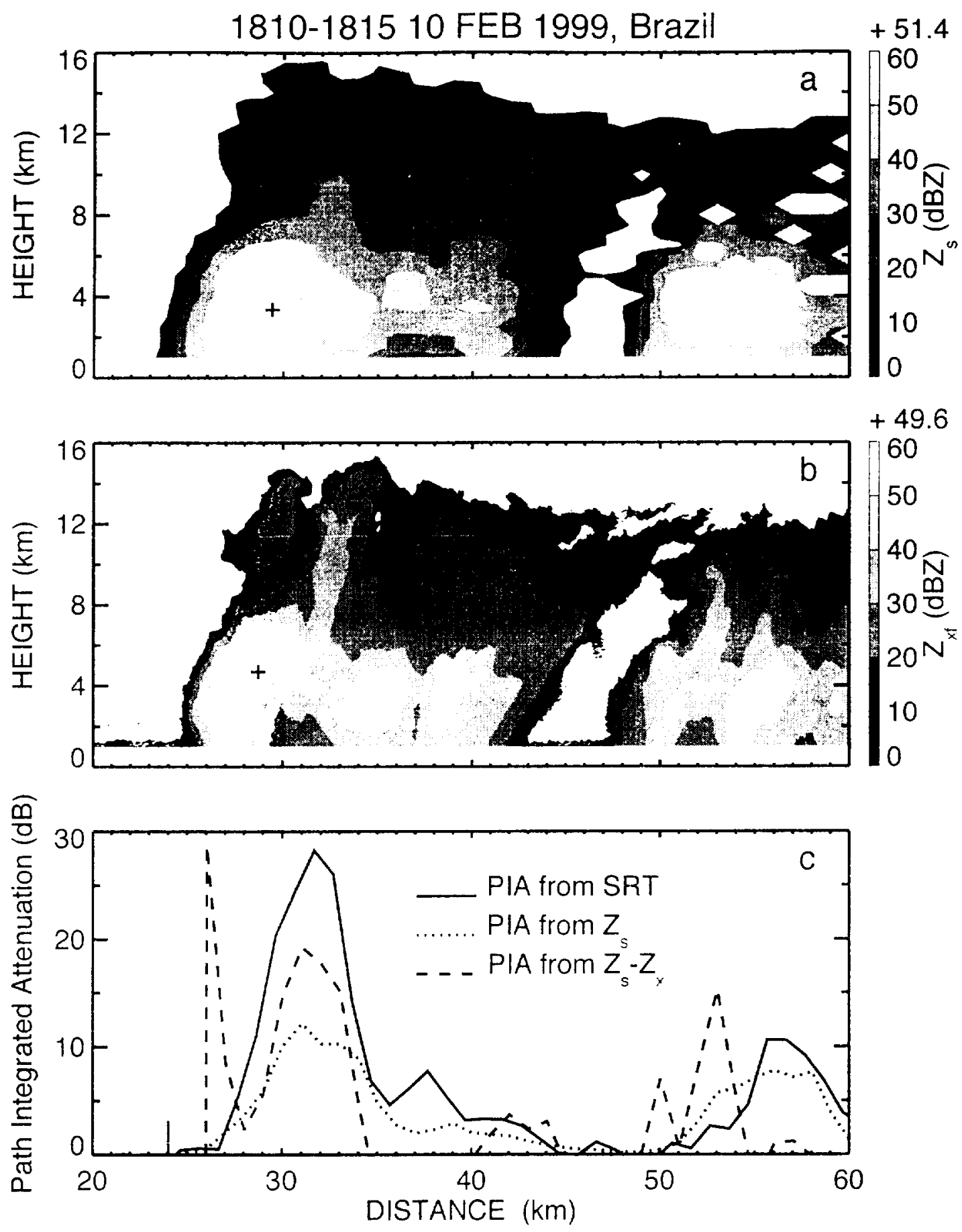

Fig. 9. Similar to Fig. 5 but for the Brazil storm. 


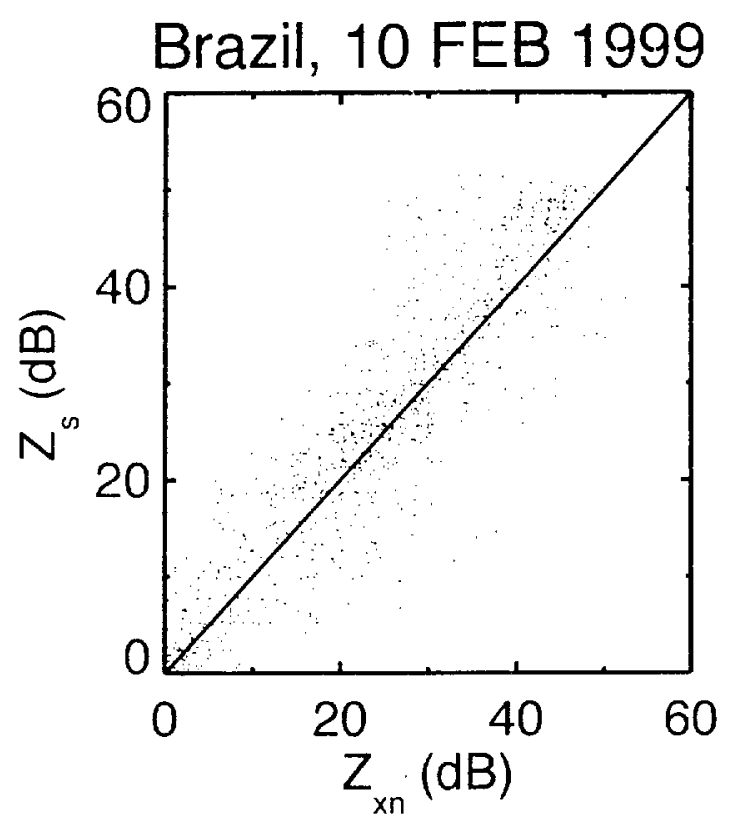

Fig. 10. Similar to Fig. 6 but for the Brazil storm. 

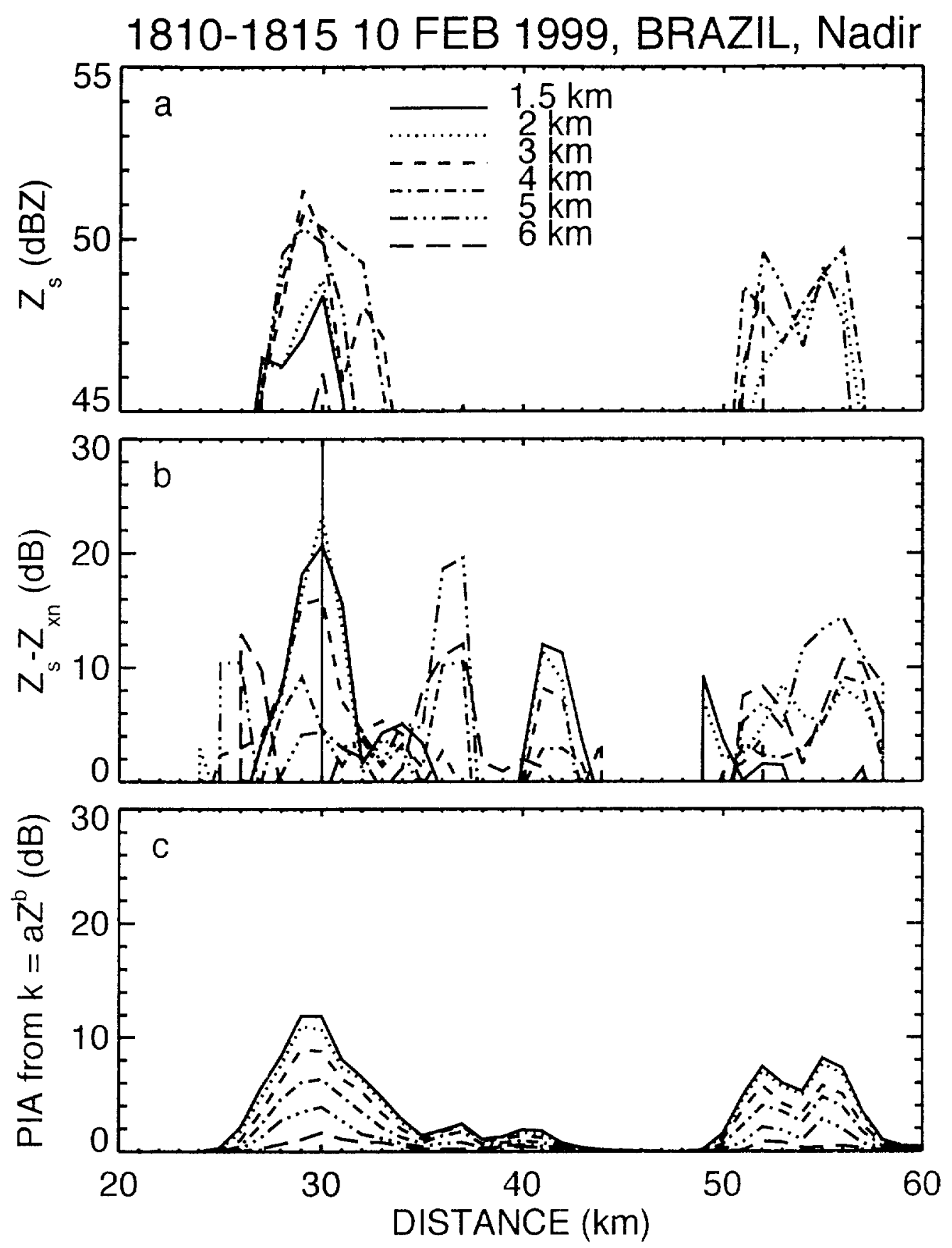

Fig. 11. Similar to Fig. 7 but for the Brazil storm. 


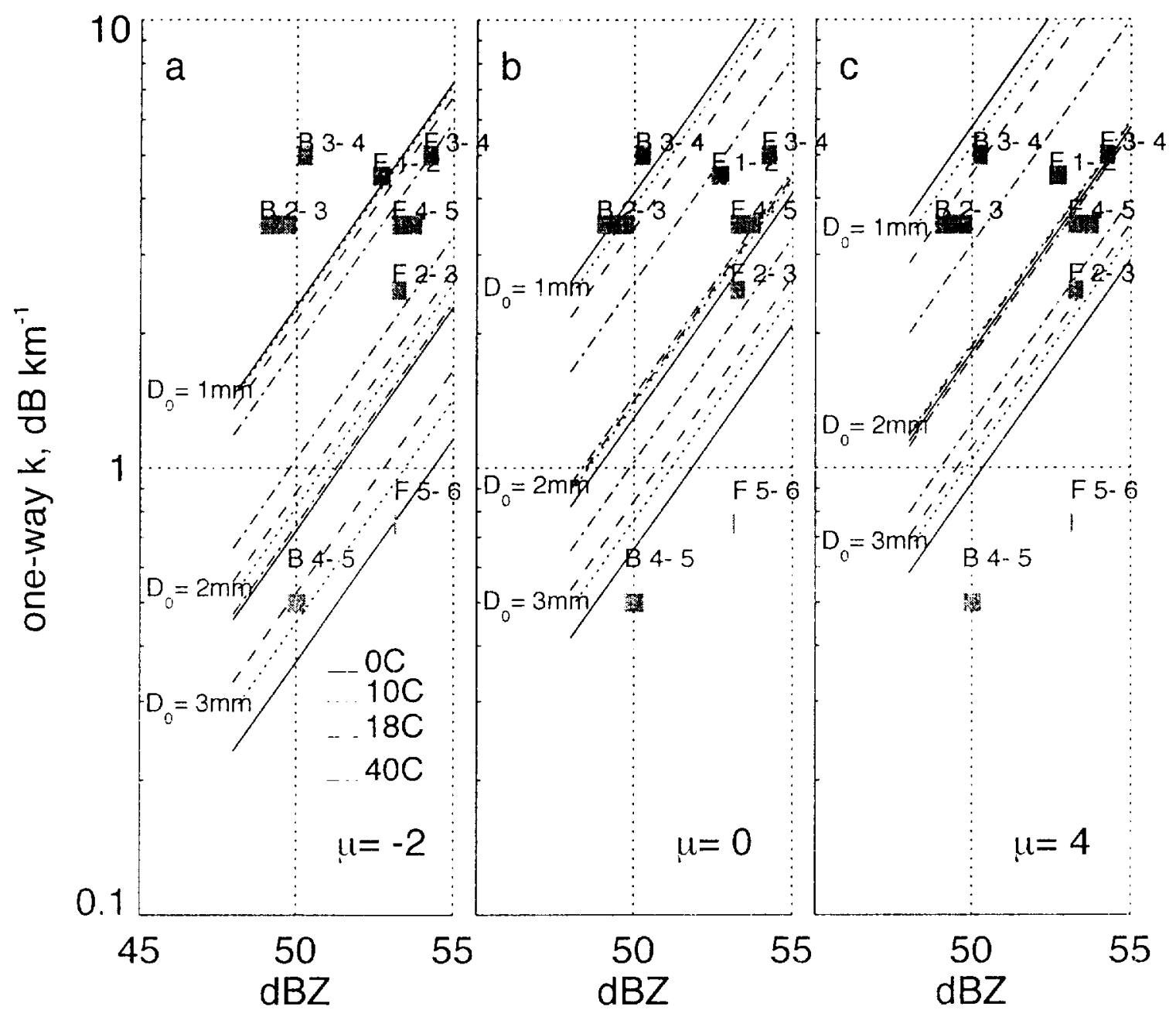

Fig. 12. Specific attenuation at $3 \mathrm{~cm}$ wavelength versus reflectivity at $10 \mathrm{~cm}$ wavelength for gamma function drop size distribution with shape parameters of (a) $\mu=-2$, (b) $\mu=0$, and (c) $\mu=4$, for median volume diameters $D_{0}=1,2,3 \mathrm{~mm}$ and temperatures of $0,10,1820^{\circ} \mathrm{C}$. The inferred specific attenuations and reflectivity along the vertical line in Fig. 7 for the Florida and Brazil are also plotted against reflectivity observed by the S-POL radar with symbols Fx and $\mathrm{Bx}$ where $\mathrm{x}$ denote the layer interval in $\mathrm{km}$. 


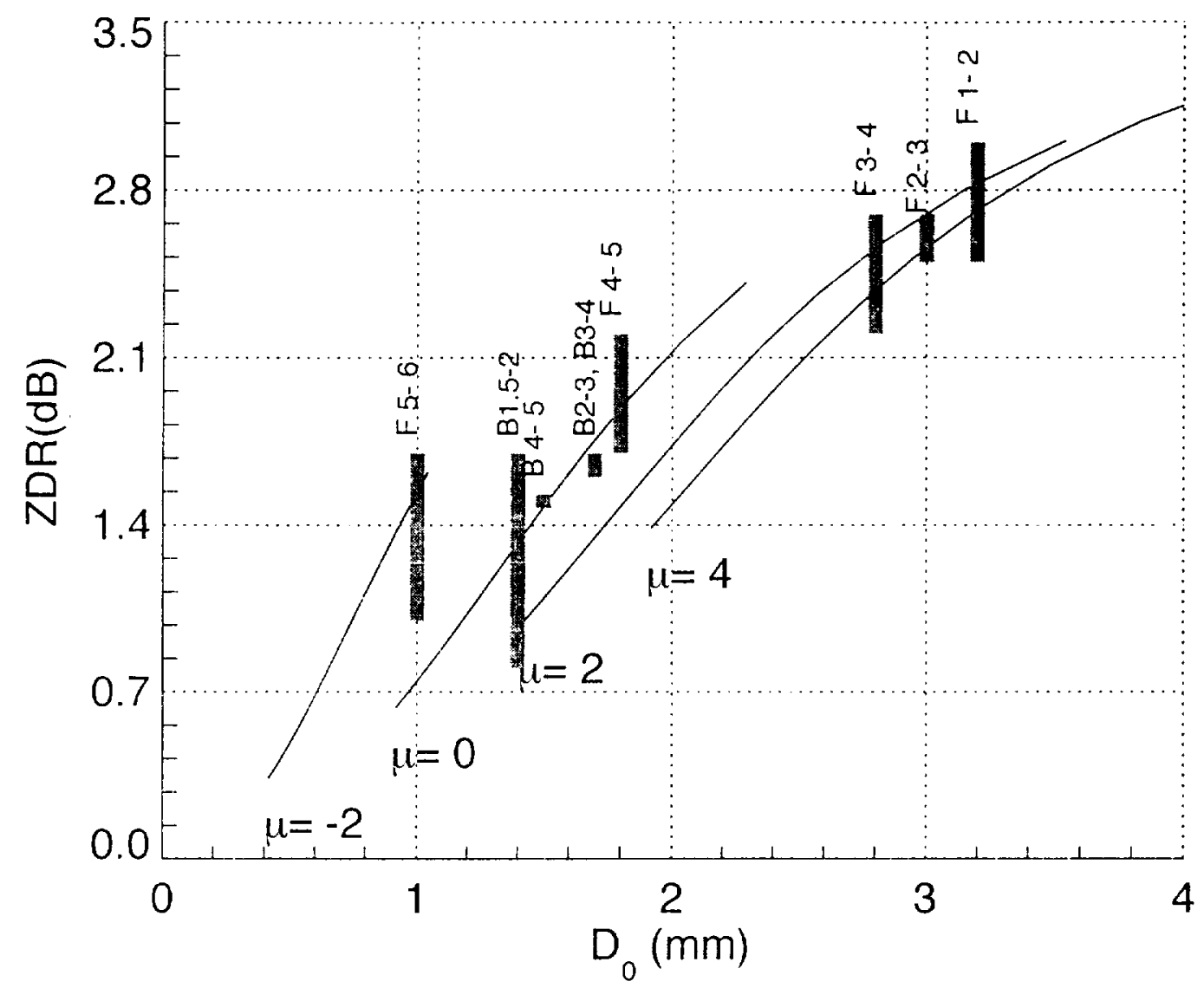

Fig. 13. Differential reflectivity, ZDR, against median volume diameter for $\mu=-2,0,2,4$ for the gamma drop size distribution. The range of median volume diameters plotted is limited by the range of slopes considered, namely, 16 to $40 \mathrm{~cm}^{-1}$. Fx and Bx specify the Florida and Brazil storms, respectively, where $x$ denote the layer interval in $\mathrm{km}$. For details, see text. 


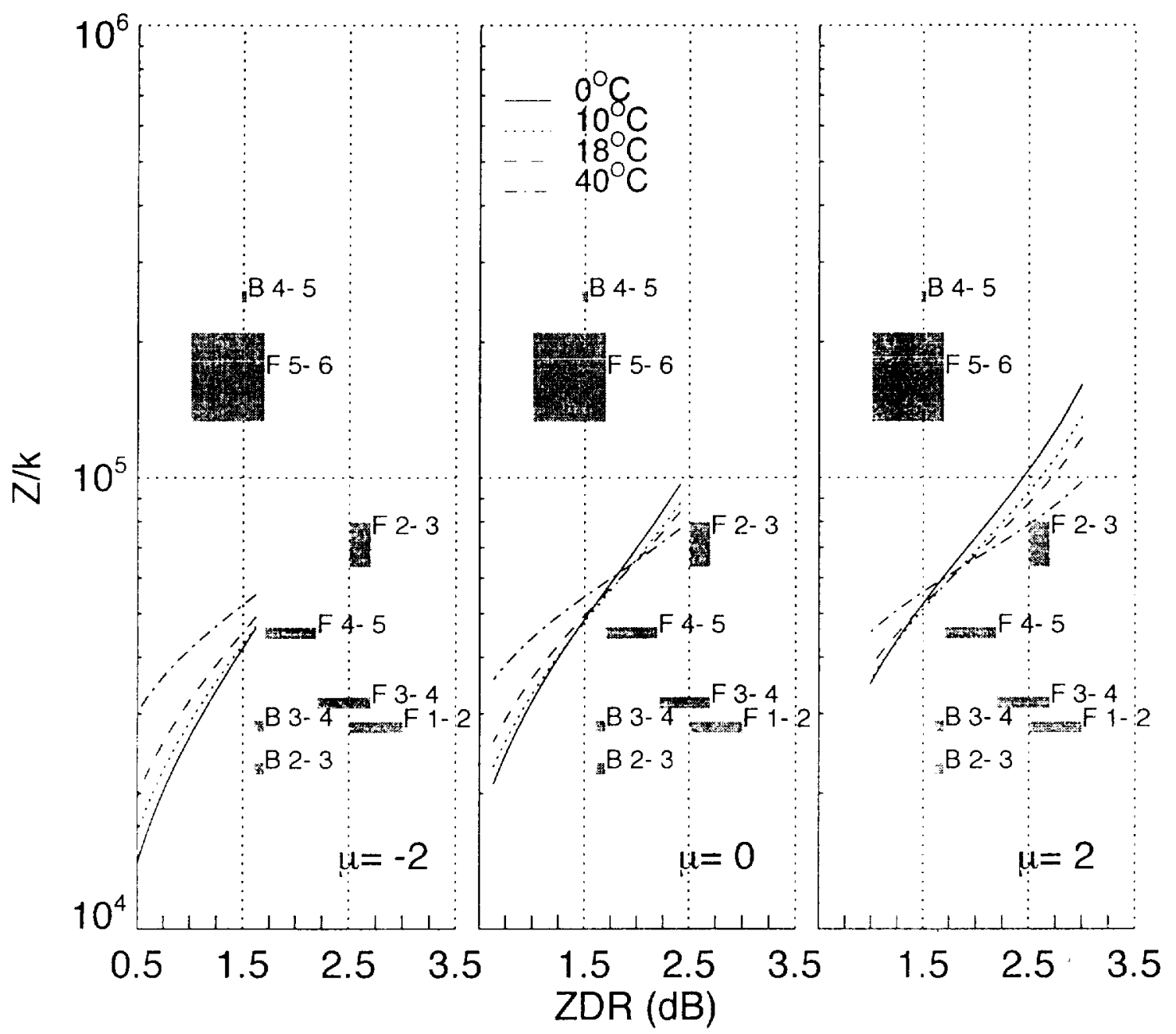

Fig. 14. Plot of $Z_{s} / k$ versus ZDR for gamma rain DSD for (a) $\mu=-2$, (b) $\mu=0$ and (c) $\mu=2$, for four temperatures. The observed 'points' are also depicted on the figures. Fx and B $x$ specify the Florida and Brazil storms, respectively, where $x$ denotes the layer interval in $\mathrm{km}$. For details, see text. 

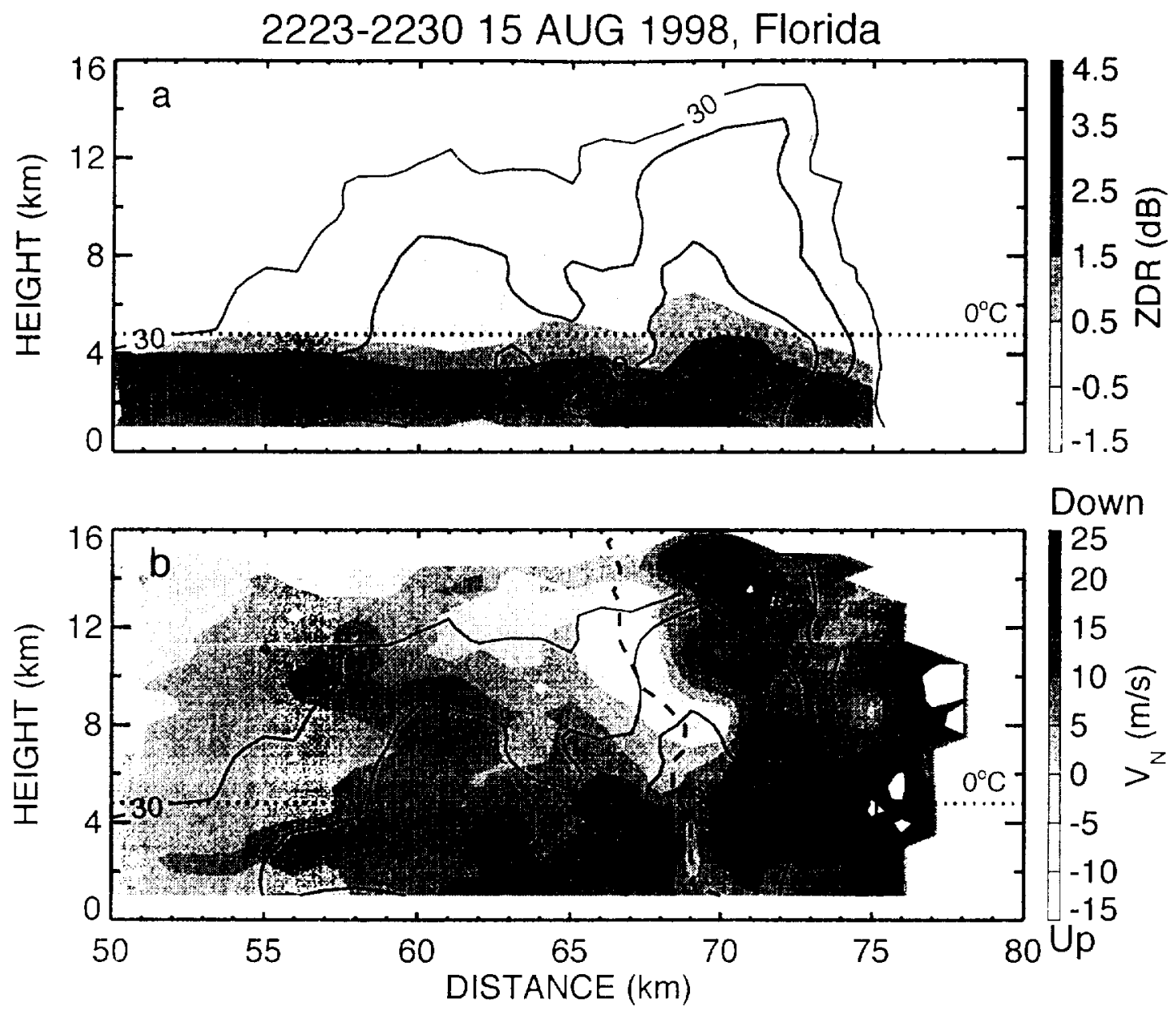

Fig. 15. Vertical cross-sections of (a) differential reflectivity and (b) nadir beam Doppler velocity for the Florida storm. S-band reflectivity contours are also shown. The melting level is indicated by dotted line. 


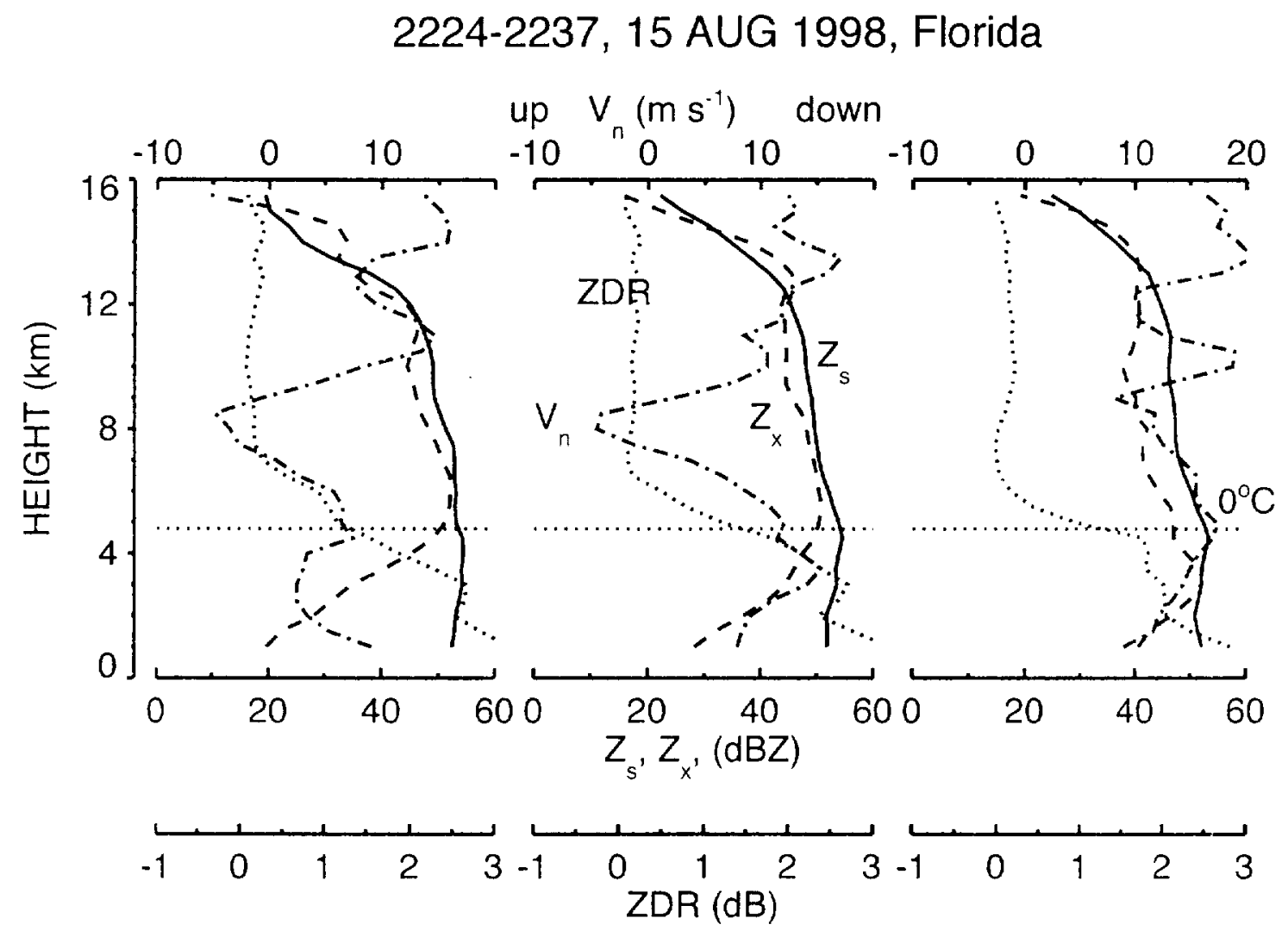

Fig. 16. Vertical profiles of S-band reflectivity (solid), X-band nadir beam reflectivity (dashes), X-band nadir beam Doppler velocity (dash-dot), and differential reflectivity (dotted) for the Florida storm. The central plot is through the region of maximum path integrated attenuation, the left plot is $1 \mathrm{~km}$ left of it, and the right plot is $1 \mathrm{~km}$ to the right of it. 

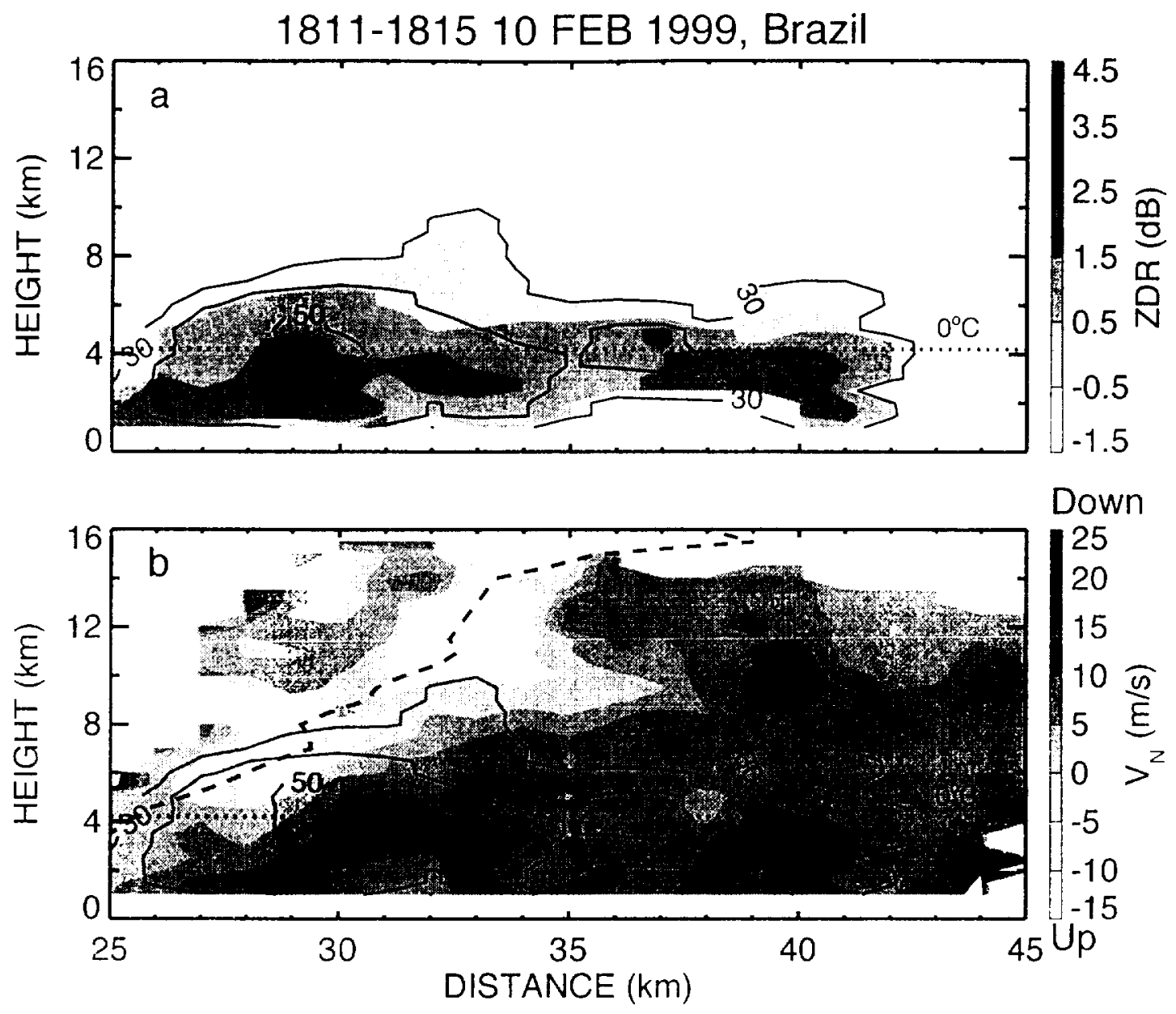

Fig. 17. Similar to Fig. 15. for the Brazil storm. 


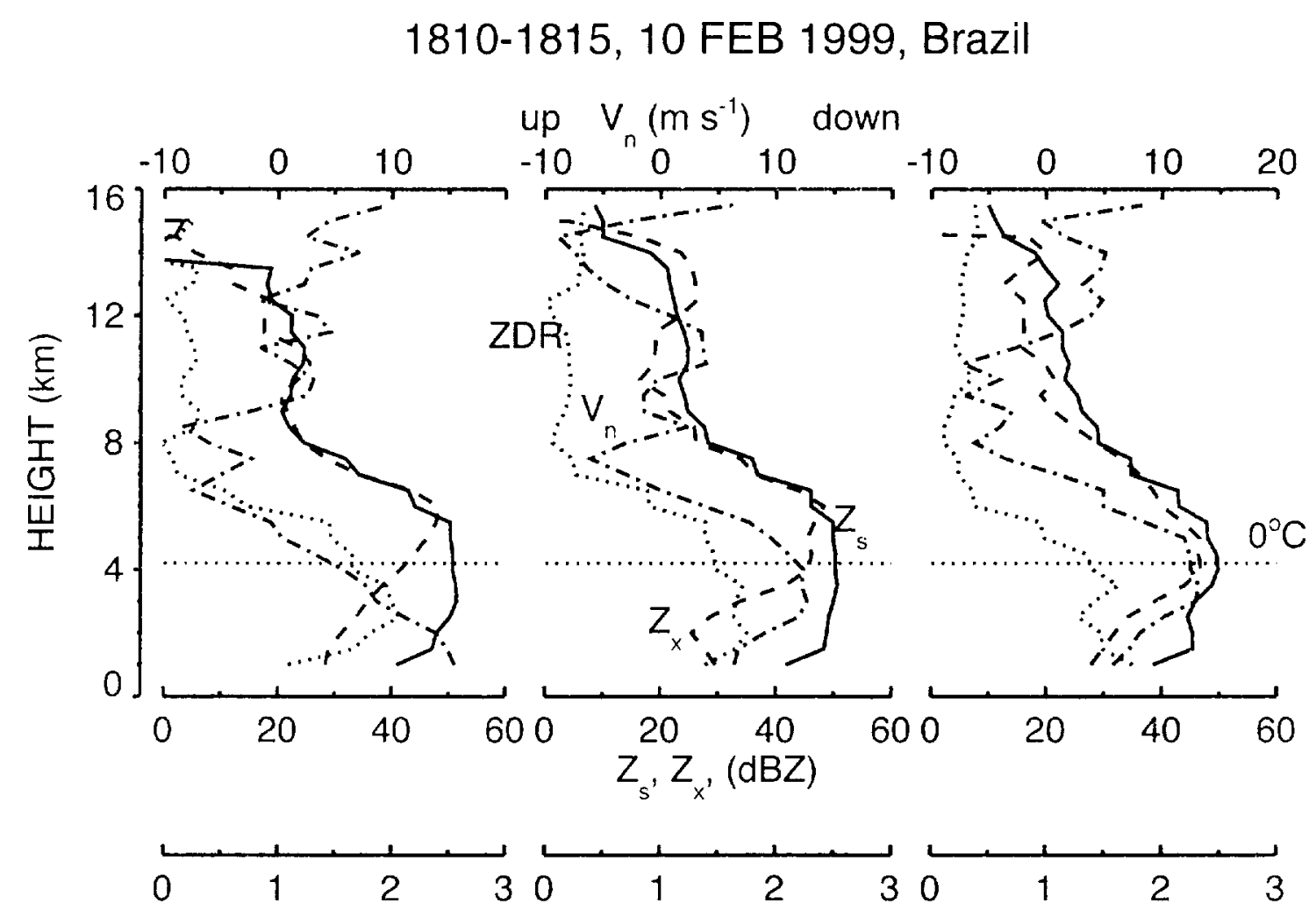

Fig. 18. Similar to Fig. 16, for the Brazil storm. 

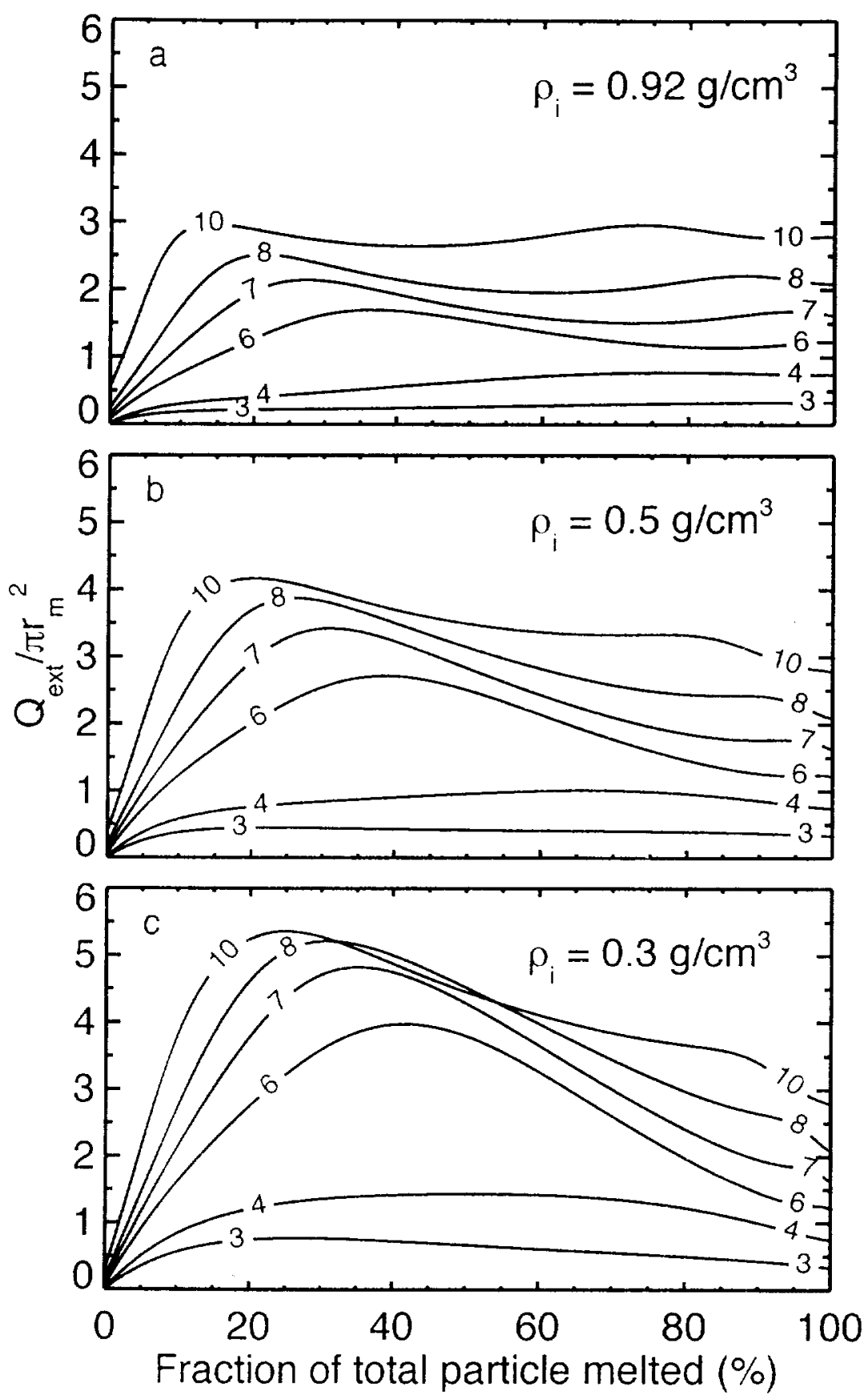

Fig. 19. Normalized extinction cross-section of melting ice particles versus fraction of mass melted for selected melted diameters of $3,4,6,7,8$, and $10 \mathrm{~mm}$ and three bulk densities of ice: a) 0.3 b/ 0.5 and c) $0.92 \mathrm{~g} \mathrm{~cm}^{-3}$. The ice particle is assumed to be spherical and melt is assumed to form a concentric sphere coat around it. The normalization is performed by the cross-section of the completely melted particle. Calculations are based on Mic theory. 


\title{
MEASUREMENT OF ATTENUATION
}

\section{WITH AIRBORNE AND GROUND-BASED RADAR IN CONVECTIVE STORM OVER LAND AND ITS MICROPHYSICAL IMPLICATIONS}

\author{
Lin Tian, G. M. Heymsfield and R. C. Srivastava \\ Submitted to: Journal of Applied Meteorology
}

\section{Popular Summary}

Rainfall over the Tropics has a significant influence to the global water and energy balance. However, direct measurements of rainfall, such as tipping bucket, only exist at sparse locations and cannot provide a complete picture of the rainfall distribution over the tropics. Alternatively, radars aboard aircraft and satellite can provide instantaneous snapshots of rainfall patterns at high spatial resolution. Radars transmit microwave energy that is reflected back toward the antenna receiver by raindrops, hail and graupel etc. The received power is used to estimate the rainfall. In the heavy rain, the received signal can be distorted or reduced substantially due to the attenuation, i.e., the loss of power as the radar signals pass through the rainfall between the target reflecting volume and the radar. The study of the attenuation can help to improve techniques for remote measurement of rainfall. In this paper, we analyzed data from two radars: a $10-\mathrm{cm}$ wavelength radar, which is subject to only weak attenuation, and a $3-\mathrm{cm}$ radar which is subject to strong attenuation. A $3-\mathrm{cm}$ radar has greater sensitivity to light-tomoderate rain and is similar to the type of radar flown in space (Tropical Rainfall Measurement Mission). Two heavy rain events that occurred in Florida and Brazil are examined. The results show that melting particles, such as graupel, not raindrops, cause strong attenuation between the $3-\mathrm{cm}$ radar and ground. 